\title{
High-fidelity numerical modelling of ocean wave energy systems: A review of computational fluid dynamics-based numerical wave tanks
}

\author{
Christian Windt*, Josh Davidson, John V. Ringwood \\ Centre for Ocean Energy Research, Maynooth University, Co. Kildare, Ireland
}

\section{A R T I C L E I N F O}

\section{Keywords:}

Wave energy conversion

Computational fluid dynamics

RANS

Numerical wave tank

\begin{abstract}
A B S T R A C T
For the research and development (R\&D) of wave energy converters (WECs), numerical wave tanks (NWTs) provide an excellent numerical tool, enabling a cost-effective testbed for WEC experimentation, analysis and optimisation. Different methods for simulating the fluid dynamics and fluid structure interaction (FSI) within the NWT have been developed over the years, with increasing levels of fidelity, and associated computational expense. In the past, the high computational requirements largely precluded Computational Fluid Dynamics (CFD) from being applied to WEC analysis. However, the continual improvement and availability of high performance computing has led to the steady increase of CFD-based NWTs (CNWT) for WEC experiments. No attempt has yet been undertaken to comprehensively review CNWT approaches for WECs. This paper fills this gap and presents a thorough review of high-fidelity numerical modelling of WECs using CNWTs. In addition to collating the published literature, this review tries to make a step towards a best practice guideline for the applications of CFD in the field of wave energy.
\end{abstract}

\section{Introduction}

WECs have a strong potential to contribute to satisfying the increasing global energy demand [1]. Developing efficient, cost-competitive and survivable WECs is the focus of R\&D efforts from both industry and academia in recent decades, and has proven to be a challenging task. An essential development trajectory to an economically competitive WEC, requires early stage optimisation and refinement of the device design and operation using numerical tools, before considering expensive physical prototype construction, deployment and experimentation [2].

\subsection{Numerical wave tanks}

A NWT is the generic name of numerical simulators for modelling nonlinear free surface waves, hydrodynamic forces and floating body motions, and have been used for many decades in ocean engineering to analyse FSI [3]. NWTs provide an excellent numerical tool for WEC R\& D, enabling a cost-effective testbed for WEC experimentation, analysis and optimisation. The fluid dynamics within the NWT are governed by the transfer of mass and momentum, described by a set of nonlinear partial differential equations, known as the Navier-Stokes equations (NSE).

Following the continual increase in available computational power, different methods for simulating the fluid dynamics within the NWT have been developed over the years, with increasing levels of fidelity, and associated computational expense. The relative accuracy and computational cost of these methods is depicted in Fig. 1.

\subsubsection{Potential flow}

Historically, solving the NSE for offshore engineering applications was computationally infeasible. Therefore, the NSE were simplified to obtain a linear potential flow (PF) equivalent, whereby solutions are generated by linearising the problem through assumptions of small amplitude oscillations, inviscid fluid and irrotational, incompresisble flow. Although PF methods have been used successfully in many offshore engineering applications [5], the linearising assumptions are challenged by realistic WEC operation, where large amplitude motions will result from energetic waves or sustained wave/WEC resonance, resulting in viscous drag, flow separation, vortex shedding and other nonlinear hydrodynamic effects.

\subsubsection{Computational fluid dynamics}

At great computational expense, CFD provides a more rigorous nonlinear treatment of the NSE [6,7]. CFD solves the NSE numerically by discretising the domains in space and time to form a system of linear algebraic equations. The spatial discretisation is implemented via a mesh, with different methods used to interpolate between mesh cells:

\footnotetext{
* Corresponding author.

E-mail address: christian.windt.2017@mumail.ie (C. Windt).
} 


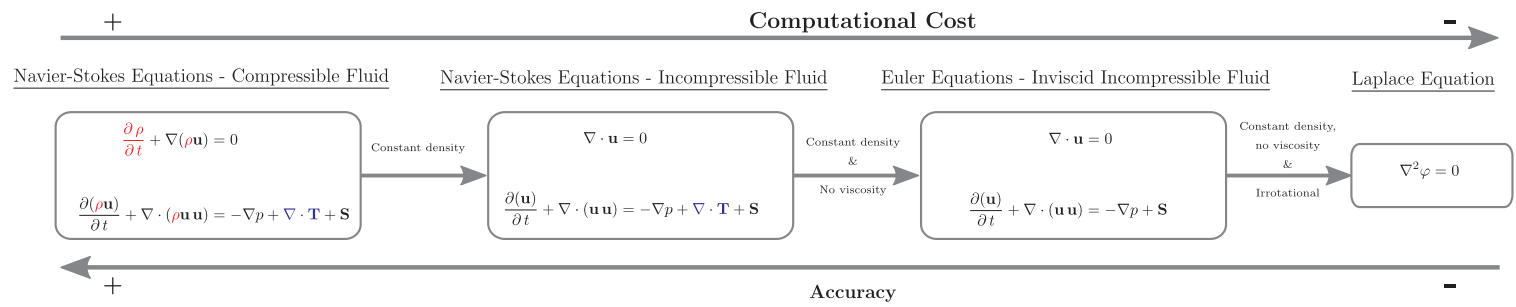

Fig. 1. Relative accuracy and computation cost of different methods for simulating the fluid dynamics within the NWT. $\mathbf{u}$ describes the fluid velocity field, $p$ the pressure. is the viscous stress tensor and the source term (adapted from [4]).

finite volume, finite difference and finite element. The temporal discretisation is achieved using timesteps. Compared to lower fidelity numerical tools, CNWTs have the advantage of capturing all relevant hydrodynamic non-linearities, such as large surface deformation, viscous drag or turbulent effects. Although CNWTs are more computationally costly, CNWT experiments deliver high resolution results, which are particularly useful for the investigation of specific flow phenomena around offshore structures.

\subsection{NWTs for WEC experiments}

Several reviews of numerical modelling approaches for WECs have been performed, in the pursuit of identifying the highest fidelity NWT experiments available for WECs:

- Li and Yu [8] specifically focus on the modelling methods of point absorbers (PAs), reviewing analytical and boundary integral equation methods, viscous drag calculation for PF solution and finally NSE methods.

- Folley et al. [9] focus on the understanding of the hydrodynamic interactions of WECs in arrays, presenting the underlying principles, strengths and weaknesses for a range of different models, covering $\mathrm{PF}$, Boussinesq and mild-slope, spectral wave and CFD models.

- Coe and Neary [10] review modelling methods for WECs in extreme seas, highlighting the unique challenges of modelling survivability, covering semi-empirical, PF, CFD and physical modelling.

- Focusing on oscillating water column (OWC) devices, Bouhrim and El Marjani [11] present modelling approaches for the flow behaviour inside the OWC chamber. The study ranges from 1D to fully 3D viscous unsteady NSE solvers.

- Day et al. [12] present a state-of-the-art review of hydrodynamic modelling approaches of Marine Renewable Energy (MRE) devices. This study covers wave energy, tidal current and offshore wind energy systems and discusses physical modelling of Power Take-Off (PTO) systems, numerical modelling of MRE devices and wind load modelling for wind turbines.

- Wolgamot and Fitzgerald [13] review the use of nonlinear hydrodynamics to analyse WEC behaviour and performance, covering partially and fully nonlinear PF, CFD and Smoothed Particle Hydrodynamics (SPH) models.

- Most recently, Penalba et al. [14] review the influence of non-linear dynamics of the entire chain of a WEC (incoming wave trains, wavestructure interaction (WSI), power take-off systems or mooring lines) and furthermore presents different approaches to model nonlinear WSI.

However, no attempt has yet been undertaken to comprehensively review CNWT approaches for WECs. To fill this gap, this paper presents a thorough review of high-fidelity numerical modelling of WECs using CNWTs.

\subsubsection{Objective of review}

There are two main objectives of the present review paper: (i) Collating the publications relating to WEC analysis performed using

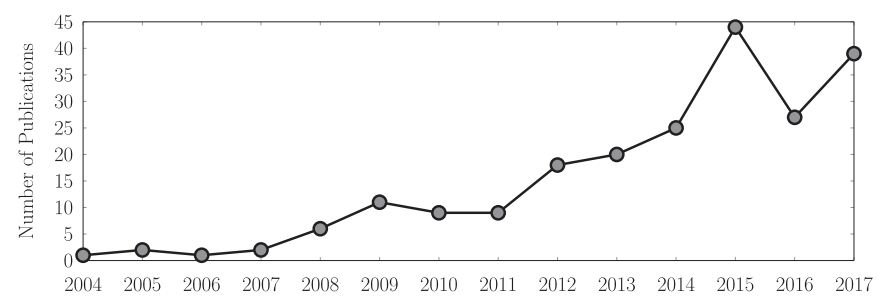

Fig. 2. Number of publications using CNWT analysis of WECs.

CNWTs, and (ii) Offering guidelines for the application of CFD for WEC experiments.

The continual improvement and availability of high performance computing, has led to the steady increase of CNWTs for WEC experiments in recent years, as shown in Fig. 2 and Table 1. The data in Fig. 2 is based on the literature collated within the present review. Table 1 acts to chronologically order the reference numbers, so that the larger the reference number in this review, the more recent the study.

\subsubsection{Framework and outline of review}

The review begins by collating the published literature pertaining to the use of CFD for WEC analysis, categorised by the different WEC device types. The various WEC operating principles and subsystems are discussed to highlight the wide variety of systems included in the CNWT simulations. The types of analysis applications the CNWTs are employed towards are also explored:

- Section 2 presents the different device types and discusses the operating principles

- Section 3 discuses the different analysis applications and WEC subsystems included in the CNWT

The technical CFD aspects of the literature are then reviewed, delving into the general requirements of a CNWT for WECs:

- Section 4 outlines the problem discretisation for the numerical solution process

- Section 5 discusses modelling different flow regimes, such as inviscid, laminar and turbulent flows

- Section 6 details wave generation and absorption

- Section 7 investigates the FSI problem

Table 1

Publications using CNWT analysis of WECs.

\begin{tabular}{llll}
\hline Year & Publications & Year & Publications \\
\hline 2004 & {$[15]$} & 2011 & {$[47-55]$} \\
2005 & {$[16,17]$} & 2012 & {$[56-73]$} \\
2006 & {$[18]$} & 2013 & {$[74-93]$} \\
2007 & {$[19,20]$} & 2014 & {$[94-118]$} \\
2008 & {$[21-26]$} & 2015 & {$[119-158]$} \\
2009 & {$[27-37]$} & 2016 & {$[159-184]$} \\
2010 & {$[38-46]$} & 2017 & {$[185-223]$} \\
\hline
\end{tabular}


Table 2

CNWT experiments considering point absorber devices.

\begin{tabular}{|c|c|c|c|c|}
\hline Point Absorber & Type & DOF & Array & Description \\
\hline$[21]$ & $g$ & $\mathrm{H}$ &.$^{2}$ & Cylindrical buoy \\
\hline$[191,192]$ & $\mathrm{g}$ & $\mathrm{H}$ & $.2,5$ & Cylindrical buoy \\
\hline$[101,149,160,164,170-172,179,189,190,202,203]$ & $\mathrm{g}$ & $\mathrm{H}$ & - & Spherical buoy \\
\hline$[47,58,126,128,165,173,205,208]$ & $\mathrm{g}$ & $\mathrm{H}$ & - & Cylindrical buoy \\
\hline$[78,128,132,200]$ & $\mathrm{g}$ & $\mathrm{H}$ & - & Box shaped buoy \\
\hline$[202]$ & $\mathrm{g}$ & $\mathrm{R}$ & - & Box shaped buoy \\
\hline$[37,52,117]$ & $\mathrm{g}$ & $\mathrm{H}$ & - & Cone shaped buoy \\
\hline$[56,120]$ & $\mathrm{g}$ & $\mathrm{S}$ & - & Box shape buoy \\
\hline [142] & $\mathrm{g}$ & $\mathrm{H}$ & - & Multi body buoy \\
\hline [139] & $\mathrm{g}$ & $\mathrm{H}, \mathrm{P}$ & - & Box shaped buoy \\
\hline$[102,202]$ & $\mathrm{g}$ & $\mathrm{S}, \mathrm{H}$ & - & Spherical buoy \\
\hline [134] & $\mathrm{g}$ & $\mathrm{H}, \mathrm{P}$ & - & Cylindrical buoy \\
\hline [210] & $\mathrm{g}$ & $\mathrm{H}, \mathrm{P}$ & - & Cylindrical spar \\
\hline$[150,212]$ & $\mathrm{g}$ & $6 \mathrm{DOF}$ & - & Spherical-bottomed buoy \\
\hline$[43,82,147,177,200]$ & $\mathrm{g}$ & $\mathrm{H}, \mathrm{S}, \mathrm{P}$ & - & Cylindrical buoy \\
\hline [206] & $g$ & $\mathrm{H}, \mathrm{S}, \mathrm{P}$ & - & Spherical buoy \\
\hline [125] & $g$ & $\mathrm{H}$ & - & Wavestar like \\
\hline [145] & s & - & - & Stationary Blow-Jet \\
\hline$[25]$ & $\mathrm{s}$ & - & - & Stationary Spiral-Reef \\
\hline [163] & $\mathrm{s}$ & $\mathrm{P}$ & - & Point pivoted absorber \\
\hline [30] & $\mathrm{s}$ & $\mathrm{P}$ & - & SEAREV \\
\hline [27-29] & $\mathrm{s}$ & $\mathrm{P}$ & - & WRASPA \\
\hline$[32,39,49,52,117]$ & $s$ & $\mathrm{H}$ & - & Manchester Bobber \\
\hline$[52,44]$ & $\mathrm{s}$ & $\mathrm{H}, \mathrm{S}$ & - & Manchester Bobber \\
\hline [143] & $\mathrm{s}$ & $\mathrm{H}$ & - & WaveBob \\
\hline [151] & $\mathrm{s}$ & $\mathrm{S}, \mathrm{H}, \mathrm{P}$ & - & CETO \\
\hline [201] & $\mathrm{s}$ & $\mathrm{S}, \mathrm{H}, \mathrm{P}$ & - & CorPower \\
\hline$[188,220,221]$ & $\mathrm{s}$ & $\mathrm{S}, \mathrm{H}, \mathrm{P}$ & - & Lysekil Project \\
\hline [157] & $\mathrm{s}$ & $6 \mathrm{DOF}$ & - & Stewart-Gough Platform \\
\hline [53] & $\mathrm{s}$ & $\mathrm{S}, \mathrm{P}$ & - & Pelican \\
\hline [95] & $\mathrm{s}$ & $\mathrm{S}, \mathrm{H}$ & - & Bristol Cylinder \\
\hline$[54,92]$ & $\mathrm{s}$ & $\mathrm{H}$ & - & OPT PowerBuoy \\
\hline [55] & $\mathrm{s}$ & $\mathrm{S}, \mathrm{H}, \mathrm{P}$ & - & OPT PowerBuoy \\
\hline$[150,213]$ & $\mathrm{s}$ & $\mathrm{H}$ & - & Wavestar \\
\hline [207] & $\mathrm{s}$ & $\mathrm{H}, \mathrm{P}$ & - & TRITON \\
\hline [187] & $\mathrm{s}$ & $\mathrm{P}$ & .2 & CCell \\
\hline
\end{tabular}

g, s for generic or specific; S,H,R,P for Surge, Sway, Heave, Roll, Pitch respectively; Array Superscript: Number of considered devices.

The end of the review contains four disparate sections:

- Section 8 outlines validation methodologies for the evaluation of the NWT accuracy

- Section 9 details the available software packages

- Section 10 presents some best practices guidelines for the use of CNWTs for WEC experiments

- Finally, conclusions are drawn in Section 11.

\section{CFD analysis of WECs}

This section collates the literature containing CFD analysis of WECs, categorised according to the device type, the device motion, and the number of devices considered (single device or an array), as detailed in Sections 2.1-2.3, respectively, and tabulated in Tables 2 and 3. Allowing motion in multiple degrees of freedom (DOFs) poses challenges to the dynamic mesh adaption methodology (see Section 7). Similarly, multi-body devices provoke solution instability by introducing enhanced mesh distortion.

\subsection{Device types}

There are well over 1000 patented WEC devices [225], with inventors and researchers conceiving a myriad of techniques to convert the raw energy from the oscillating ocean surface into useful electricity. WECs can be broadly classified into several categories based on their operating principle. The European Marine Energy Centre [226] defines the following groups of device types: PA, terminator, attenuator, oscillating wave surge converter (OWSC), OWC and pressure differential, which are depicted in Fig. 3.

A PA is characterised by its small size compared to the wavelength, absorbing power from the wavefield analogously to antennas in electromagnetic wavefields. Terminators are aligned parallel to the incident wave fronts, being geometrically wide to intercept and stop as much of the incoming wave as possible. Attenuators are aligned perpendicular to the incoming wave and utilise the phase difference along the length of the wave to derive power through relative movement between WEC subsections. OWSCs extract power from the horizontal wave motion, typically oscillating around a hinge point. OWCs operate by converting wave energy into pneumatic energy, whereby oscillating water levels inside of a chamber force entrapped air through a turbine. Pressure differential devices are located below the ocean surface and utilise the change in pressure caused by passing waves to pump fluids through a system.

A further classification of the literature regards whether generic or specific WECs are considered. While generic devices are mostly considered during fundamental academic research, specific devices are considered to support the design and commercialisation of that specific WEC.

\subsection{Device motion}

WEC motion within the CNWT presents a challenge, not only requiring the calculation of the WEC dynamics, but also an adaptation of the CFD mesh to the WEC motion (see Section 7.1). Hence, classifying WECs based on motion constraints, namely single DOF (sDOF) or multi 
Table 3

CNWT experiments considering OWSCs, terminator, attenuator, pressure differential and OWC devices.

\begin{tabular}{|c|c|c|c|c|}
\hline OWSC & Type & DOF & Array & Description \\
\hline$[15,17,122,123,202]$ & $\mathrm{g}$ & $\mathrm{P}$ & - & Flap-type OWSC \\
\hline [176] & $\mathrm{s}$ & $\mathrm{P}$ & - & WaveRoller \\
\hline$[68,69,85,86,90,91,97,103,116,152,158,169,184,180,216,224]$ & s & $\mathrm{P}$ & - & Oyster OWSC \\
\hline Terminator & Type & DOF & Array & Description \\
\hline$[23,60,112,115]$ & $g$ & - & - & Overtopper \\
\hline$[74,94,119]$ & $\mathrm{s}$ & $\mathrm{R}$ & - & Single-Bucket Wave Turbine \\
\hline [133] & $\mathrm{s}$ & $\mathrm{P}$ & - & Seaspoon \\
\hline [121] & $\mathrm{s}$ & - & - & Seawave Slot-cone Generator \\
\hline$[26,36,131]$ & $\mathrm{s}$ & - & - & Wave Dragon \\
\hline [185] & $\mathrm{s}$ & $\mathrm{H}, \mathrm{P}$ & - & WaveCat \\
\hline [77] & $\mathrm{s}$ & - & - & CycWEC rotating Hydrofoil \\
\hline Attenuator & Type & DOF & Array & Description \\
\hline$[100,102,122,161]$ & $\mathrm{g}$ & $\mathrm{R}$ & - & Rectangular Barge \\
\hline$[80,214]$ & $\mathrm{g}$ & $6 \mathrm{DOF}$ & - & Rectangular Barge \\
\hline [146] & $\mathrm{g}$ & $\mathrm{H}, \mathrm{S}$ & - & Multibody \\
\hline [162] & $\mathrm{g}$ & $\mathrm{H}, \mathrm{P}$ & - & Twin-Raft \\
\hline [154] & $\mathrm{s}$ & $\mathrm{H}$ & - & M4 \\
\hline [71] & $\mathrm{s}$ & $\mathrm{H}$ & - & Vigor \\
\hline Pressure Differential & Type & DOF & Array & Description \\
\hline [112-114] & $\mathrm{g}$ & - & - & Fixed horizontal plate WEC \\
\hline$[105,174]$ & $\mathrm{s}$ & - & - & Bombora \\
\hline OWC & Type & DOF & Array & Description \\
\hline$[18,22,24,33,34,38,41,45,48,51,61,63,64,73,76,88,106,107,118,130,140,141,144,159,167,186,222]$ & $\mathrm{g}$ & - & - & fixed at far field boundary (FFB) \\
\hline$[50,59,70,79,87,96,104,110,112,136,138,153,166,167,193-197,217-219]$ & $\mathrm{g}$ & - & - & fixed in domain centre \\
\hline$[108,209]$ & $\mathrm{g}$ & $\mathrm{H}$ & - & Heaving OWC \\
\hline$[198,199]$ & $\mathrm{g}$ & $\mathrm{H}, \mathrm{S}, \mathrm{P}$ & - & Floating-moored OWC \\
\hline$[155,181,215]$ & $\mathrm{s}$ & - & - & REWEC \\
\hline$[42,46,57,67,93,109,211]$ & $\mathrm{s}$ & - & - & Direct Drive Tubrine (DTT) \\
\hline [148] & $\mathrm{s}$ & - & - & PICO \\
\hline$[81]$ & $\mathrm{s}$ & $\mathrm{S}, \mathrm{H}, \mathrm{P}$ & - & OWEL \\
\hline
\end{tabular}

g, s for generic or specific; S,H,R,P for Surge, Sway, Heave, Roll, Pitch respectively; Array Superscript: Number of considered devices.

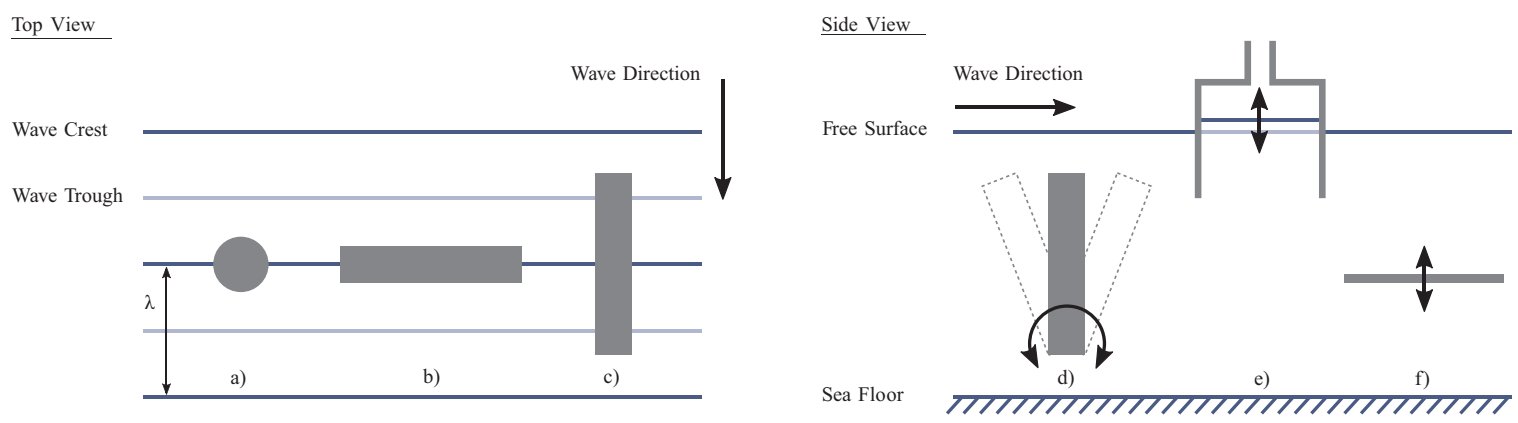

Fig. 3. Different WEC categories: a) PA; b) Terminator; c) Attenuator; d) OWSC; e) OWC; f) Pressure Differential.

DOF (mDOFs), is helpful in order to evaluate the required model complexity. On this note, OWCs deserve special attention, being predominately represented by a fixed structure, characterised with no DOF. An additional category of fixed structures can be included embracing e.g. horizontal or vertical cylinders, that are mostly considered for extreme load analysis. Relevant studies for the wave energy field are found in $[8,19,37,40,49,52,62,72,84,99,117,135,137,150,160$, $173,178,183,212]$.

\subsection{Arrays}

To contribute significant amounts of power to the electrical grid, WECs must be deployed in large arrays or farms. Thus, understanding the hydrodynamic interaction between devices within the array is an important problem, which can be investigated using a NWT. The reviewed literature will therefore also be categorised in a binary way, differentiating between studies considering WEC arrays or not. Due to the increased computational burden when modelling WEC arrays, it can be anticipated that only a few studies tackle this problem using a CFD approach.

\section{Analysis applications and WEC subsystems}

Since CFD simulations are several orders of magnitude more computationally demanding than low- or mid-fidelity hydrodynamic models, the use of CNWTs for WEC experiments must be well justified by the application to which they are employed. Section 3.1 details the different WEC analysis applications found within the CNWT literature. 
Furthermore, within the groups of applications, the CNWTs may differ in terms of the WEC subsystems included in the simulations. Apart from the WEC body, the most prominent subsystems are the PTO, mooring and control systems. The interaction between subsystem models, increases the model complexity and potentially the computational burden. A more detailed discussion of the different subsystems is given in Section 3.2.

\subsection{Anaylsis applications}

The following WEC analysis applications can be identified from the CNWT literature: evaluation of viscous (drag) effects, performance analysis, optimisation, code assessment, (extreme) loads estimation, scaling, system identification, control evaluation, and conceptual design.

\subsubsection{Viscous effects}

A significant advantage of CNWTs is the inherent consideration of viscosity in the NSE, which clearly separates CFD from low-/mid-fidelity models. Hence, one of the main CNWT applications is the analysis of viscous effects.

In $[47,56,97,120,146,151]$, CNWT simulations are used to identify the viscous damping term in the Morrison equation. In a study on a moored generic PA, Palm et al. [82] investigate the effect of viscosity on the mooring loads by employing both Reynold Averaged Navier-Stokes (RANS) and Euler simulations. Differences between viscous and inviscid simulations are found to be dependent on the treated DOF. Studying wave-induced roll motion of a rectangular barge, authors in $[100,122,161]$ find significant differences between laminar CNWT simulation and PF theory. It is found that PF over predicts the roll motion around the natural frequency $\omega_{N}$ and further under estimates roll motion for $\omega<\omega_{N}$. The same authors extend their study to hydrodynamic performance of an OWSC, comparing RANS and PF results to analyse the effect of viscosity [122,123]. PF overestimates mean power and efficiency.

To determine the significance of viscous losses during operation of an OWSC, authors in $[90,224]$ investigate the wavefield around the flap, and study the effect of viscosity when including the PTO damping. From the (qualitative) wavefield analysis it is concluded that vortex shedding is a short lived phenomenon of half a wave cycle. Furthermore, the authors provide a thorough discussion of the importance of including/excluding viscous effects based on the two dimensionless measures: Keulegan-Carpenter number $\left(K C=\frac{2 \pi A}{l}\right)$ and diffraction parameter $\left(K l=\frac{2 \pi l}{\lambda}\right)$, with wave amplitude $A$, wavelength $\lambda$ and characteristic length $l$. Based on the discussion in [224], Dolguntseva et al. [188] perform a similar comparison study for a mDOF PA in viscous and inviscid fluids. Again using $K C$ and $K l$, regular and irregular sea states can be identified for which significance of viscous effects can be assumed. However, comparison of hydrodynamic forces and other data such as WEC displacements, reveals negligible influence of viscous effects.

Stansby et al. [154] also investigates viscous drag coefficients, aiming for drag minimisation of the M4 device. Flat and round based float shapes were considered, highlighting a significant power output increase for the latter. Eskilsson et al. [131] compares viscous (employing RNG $k-\varepsilon$ turbulence model) and inviscid simulations for a full scale overtopping type device (Wave Dragon), revealing potentially misleading results when viscosity is omitted.

\subsubsection{Performance}

CNWT experiments can be utilised to assess WEC performance, calculating important metrics such as power absorption and efficiency. The performance analysis therefore requires simulation of the overall WEC system including PTO, mooring and/or control strategy. From the reviewed literature it becomes apparent, that the modelling fidelity of these WEC subsystems varies significantly and that no study includes a full wave-to-wire model.

The performance of stationary OWC devices have been assessed in many studies (see Table 3), owing to the simplicity of modelling this type of WEC in a CNWT. Here the PTO is generally represented as a simple pressure outlet (i.e. orifice), and analysis of the OWC geometry or PTO characteristics is performed. An example of a comprehensive optimisation analysis can be found in the series of studies $[166,193,194,196,197]$, where, after validating the OWC model, effects of the front lip submergence, РTO orifice shape and size, as well as model scaling and air compressibility, on the OWC performance are investigated. Slightly more sophisticated PTO representations are delivered by modelling porous media inside the OWC chimney, see for example [107,130,140,141,159]. Complex PTO representations are presented in $[46,67,93,109,139,211]$, considering direct drive turbines. However, again, avoiding wave driven motion for the fixed structure, which keeps the computational burden low. Only [81,198,199] are found to investigate a floating OWC device, moreover including mooring analysis.

Considering a cylindrical PA, Agamloh et al. [21] investigate the power output through a linear damper PTO system. The study considers both a single device and an array-like arrangement of two devices, revealing that a phase shift between the in-line bodies leads to low power output for one buoy and high power for the other. Investigating a submerged, spherical PA in steep waves, Anbarsooz et al. [95] calculate the efficiency for a linear spring-damper type PTO system. It is found, that for increasing wave height $(H)$, the efficiency decreases and the maximum efficiency shifts towards higher frequencies. Also, optimal spring and damping values are evaluated, showing discrepancies compared to linear theory. Ref. [202] simulates a PA, including mooring and PTO system represented through a simple spring-damper system, and power absorption and efficiency are determined for varying PTO damping values. Studies $[54,92]$ consider a simplified, multi-body model of the OPT PowerBuoy, coupled through a spring-damper PTO system, absorbed power is evaluated for varying spring-damper values. More sophisticated system representation is considered for the Lysekil Project PA [188], where the inclusion of mooring characteristics and stroke-length control of the linear damper PTO system, allows more realistic power assessments.

CNWT experiments have also been applied for the assessment of more unconventional WEC devices, for example Eskilsson et al. [131] investigate the overtopping discharge of the Wave Dragon and Caskey and Jeans [77] analyse the CycWEC by the means of pressure and force coefficients for its hydrofoils.

Generally, it can be seen that, except for fixed OWCs, CNWT WEC models do not yet reach a level of sophistication, for the entire wave-towire system, at which comprehensive performance analysis and optimisation can be performed. This can mainly be reasoned by the time consuming verification and validation processes, and the lack of highfidelity models for subsystem components such as non-linear PTO, mooring and control systems.

\subsubsection{Optimisation}

For WEC optimisation studies, a large number of simulations, with varying parameters (device shape, PTO setting, wave conditions), are necessary. Thus, fast-computing low- to mid-fidelity numerical models are preferable. However, if nonlinearities are prevalent in the systems being optimised, then high-fidelity models must be employed.

CNWTs have been utilised for the optimisation of OWCs $[59,136]$. To reduce the number of required simulations, authors in $[76,186]$ propose sequential optimisation where a recurrent procedure is employed. Optimising on PTO orifice, OWC chamber size, front wall thickness and immersion depth, a total of 168 simulations are performed, showing for given wave conditions, that optimal OWC characteristics can be determined. However, the studies only consider a $2 \mathrm{D}$ fixed OWC structure, so it is yet to be determined if the method can 
deliver meaningful results at acceptable computational cost for 3D, more complex and dynamic structures.

Schimtt et al. [86] performs a shape optimisation study for OWSCs, considering five different flap geometries. It is noted that although CNWT optimisation studies can only be used to limited extents, they can guide the design of subsequent physical wave tank experiments. The same authors also perform an optimisation study on the OWSC PTO damping coefficient [180], revealing that optimal damping values do not scale linearly with wave height, therefore PF-based simulations will provide suboptimal results.

For a structural optimisation, regarding loads and stresses on the structure and material, study [125] performs an optimisation study on the float and arm of a Wavestar like PA.

\subsubsection{Code assessment}

Code assessment, by means of proof of concept and validation holds the biggest share of published CNWT applications. Therefore, some examples are discussed here and a more comprehensive discussion of the applied methodologies for validation is given in Section 8.

Aiming at modelling the Bombora WEC, authors in [105,174] include a FSI methodology for the device's flexible membrane. Here, results can be considered as first proof of concept. Furthermore, comparing coupled and uncoupled FSI models, it is found that more efficient uncoupled models may already deliver meaningful results. Iturrioz et al. [79] use CNWT results as an accuracy benchmark to assess a novel, time-domain model for OWCs, which is calibrated using CFD data by the means of friction and discharge coefficients. It is concluded that the more efficient time-domain model should be used for initial analysis whereas CNWTs should be applied for specific, nonlinear problems.

Focusing on the back-end of CNWTs, authors in [19,43,102,148] present different novel numerical approaches to solve the NSE. Here, the modelling of WECs is the driver for the development and/or deliver case studies for code verification and validation. Considering code comparison, authors in $[38,88,117]$ employed various numerical solvers. A more detailed discussion of the code comparison is presented in Section 9.

\subsubsection{Load estimation}

As specified by numerous authors (e.g. $[37,173]$ ), the use of CFD for the analysis of WECs is well justified when considering extreme loading and extreme sea states. These conditions push low- and mid-fidelity models beyond their limits. Hence, (extreme) load estimation of WECs can be stated as another major field of application for CNWTs.

In the reviewed literature, different types of extreme load cases are considered which can be differentiated by the wave condition, the WEC or the modelling approach. Extreme load estimation on rigid structures has been performed in $[37,52,84,99,117,121,122,173,212]$. Further, dynamic structures such as flap-type WECs $[68,85,103,116,158,169,184]$ or PA $[37,44,49,117,151,188,212,213,220,221]$ are considered. The analysed sea states span regular waves $[37,52,68,85,103,116,117,158,184,169]$, irregular waves $[121,188]$, tsunami $[220,221]$ and (focused) wave groups $[37,39,49,52,83,84,89,99,117,122,151]$. The work in $[83,84,212,213]$, summarised in the dissertation of [150], provides a comprehensive study of CNWT assessment of extreme loads on WECs, considering cases ranging from waves-only, waves incident on fixed structures, to waves incident on oscillating WEC bodies, concluding that CFD is well suited for extreme load analysis.

\subsubsection{Scaling}

During the physical testing of WECs, engineers mostly rely on scaled models. To appropriately scale dimensions of the structure and wave characteristics, the Froude scaling law is applied. However, global constants, such as gravity or fluid viscosity, can not be correctly scaled, leading to a discrepancy between Froude and Reynolds scaling, which undermines the confidence in upscaling the results from physical tank tests. To overcome this scaling issue, full scale testing must be conducted, requiring immense capital expenditure. A powerful feature of CNWTs, is the ability to easily change the scale of the considered system, at virtually zero cost compared to physical testing. Within the CNWT both structural dimensions and wave conditions can be scaled, and also global constants (gravity, fluid viscosity) can easily be adjusted.

Wei et al. $[90,224]$ investigate scaling effects on an OWSC, for cases of an undamped, damped and fixed flap in regular seas. Negligible differences are found for scales 1:1, 1:25, 1:50 and 1:100. However, differences can be observed when analysing the flow field around the flap in terms of vorticity, leading to higher dynamic pressures at full scale. But due to the higher order of scale independent hydrostatic pressure, effects on the global performance vanish. The authors point out that the lack of physical full scale data makes the "numerical results [...] unverifiable".

Schimtt and Elsässer [216] investigates the application of Froude scaling to model test of OWSCs by changing the viscosity of the fluid in the CNWT while retaining the dimensions of the structure and tank. The authors highlight the importance of mesh adaption when considering different scales in order to capture boundary layer phenomena at all scales. This leads to much finer mesh resolution in vicinity of the flap for the full scale tests. Comparing rotation angles and power output, $2 \%$ respectively $3 \%$ deviation is found between full and model scale. Furthermore, differences in terms of flow separation and vortex shedding is observed.

Performing drag identification tests for various scaled models, Mundon et al. [207] states, for high KC and low Re (see Section 5), scaling can be applied successfully. For lower KC, the scaling rules fail, leading to overestimation of the results.

Investigating OWCs, Elhanafi et al. [195] studies the influence of scale, as well as air compressibility, on the absorption efficiency, for regular waves. The scaling effects are negligible when considering incompressible air, however, full scale simulations with compressible air show a $12 \%$ reduction of maximum absorption efficiency.

\subsubsection{System Identification}

System identification (SI) allows WEC hydrodynamic models to be determined from recorded data of the WEC behaviour. The SI procedure comprises four steps [164]:

i) Choose a parametric structure for the model

ii) Synthesise a suitable input signal to the system

iii) Record the resulting output signal from the system

iv) Determine optimal model parameters through an identification algorithm using the input/output data

To obtain the input/output data, the dynamic behaviour of the WEC can be simulated in a CNWT. Although CNWT experiments can be computationally costly, the CFD simulation has only to be run once to produce the data, and then the parametric model identified from that data can achieve the same level of fidelity as the CFD simulation, but with a fraction of the computation time.

The authors in $[78,126]$ identify state-space models for a heaving PA using signals generated from a free decay experiment in a CNWT. Similarly, Armesto et al. [96] employs SI to determine a state-space model of an OWC. More recently [101,135,149,172] employed SI for the determination of discrete time models for heaving PAs. Ringwood et al. [179] details the identification of hydrodynamic models for WECs using CNWT experiments.

\subsubsection{Control evaluation}

By increasing the energy capture across changing sea states, energy maximising control systems (EMCSs) can improve the economic viability of the WEC. An EMCS effectively tunes the WEC dynamics to resonate with the incident waves, resulting in increased amounts of 
absorbed energy due to larger WEC motions. The large amplitude motions result in viscous drag, flow separation, vortex shedding and other nonlinear hydrodynamic effects. Simulating a WEC under controlled conditions, therefore requires a realistic simulation environment, such as a CNWT.

Evaluating the performance of an EMCS classically relied on linear hydrodynamic model simulations. However, recently a number of studies have begun to incorporate EMCSs into CNWT experiments to allow a more realistic evaluation of the EMCS performance. In $[170,189,190]$ modify the CNWT setup outlined in [126], to implement and evaluate different control strategies. Giorgi and Ringwood [170] describe the implementation of latching control in a CNWT, which is used to evaluate optimal latching duration for a heaving PA in regular waves. Davidson et al. [189] implement proportional-integral (PI) control, where the PI parameters are selected using SI techniques from [126,164]. Comparing the CNWT results against PF simulations shows that the PF simulations overestimate the WEC motion and power absorption. In [190], an adaptive EMCS, based on a receding-horizon pseudospectral optimal control (RHPC) formulation, is implemented and evaluated in a CNWT. Here, on-line SI methods are employed in the control algorithm, to identify and update the linear control model during the simulation, creating a best fitting linear control model representative of the nonlinear conditions in the CNWT.

\subsubsection{Conceptual design}

During early stage R\&D of WECs, fast-computing low- to mid-fidelity numerical models are generally used. Fast computation allows for numerous iterations during the conceptual design process. However, the validity of fast-computing models may reach their limit in certain circumstances, such as consideration of complex geometries or system dynamics, therefore high-fidelity CNWT models must be employed. For example, authors in $[74,94,119]$ use a CNWT to prove the device concept for a novel single bucket wave turbine.

\subsection{WEC subsystems}

In addition to the WEC body, a WEC can be further decomposed into subsystems, including the PTO, mooring and control systems. Depending on the device and analysis application, certain subsystems must be included, or may be omitted, in the CNWT simulation. The PTO system is inherently required to assess the power output of a WEC, hence has historically been the first subsystem included into CNWTs. In contrast, only recently mooring in $[81,82,147,157]$ and control systems in $[170,171,188,201]$ have been implemented and considered in CNWT WEC experiments. Generally, the implementation of high-fidelity models for the WEC subsystems are desired, to justify the enhanced cost for CFD simulations, otherwise the inclusion of lower fidelity WEC subsystem models will undermine the accuracy of the high-fidelity hydrodynamic model.

\subsubsection{PTO}

A range of different model fidelities are implemented for the representation of the PTO subsystem within a CNWT. An overview of the various PTO representations is given in Section 3.1.2, where the simplest implementation is found for OWC devices, for which the PTOs are modelled as orifices or porous media in the OWC chimney. More complex representations are considered by modelling Savenious-type rotors inside the OWC chamber. For other WEC types, most prominently linear (spring) damper systems are employed for the PTO representation e.g. $[21,69,82,85,90,95,122,123,151,171,176,188,224]$. However, no study has been found to implement a more realistic non-linear PTO system to perform wave-to-wire modelling. Especially for studies on the performance of WECs, the implementation of non-linear PTO systems is of crucial importance in order to justify the use of CNWT. Employing a costly high-fidelity CFD solution is unjustified, if only unrealistic, linear PTO systems are considered.

\subsubsection{Mooring}

The mooring system provides station keeping (passive mooring) or directly influences the system dynamics (active mooring) and power extraction method (reactive mooring). A comprehensive review of mathematical mooring models for WECs is given in [227]. From the reviewed literature it can be seen that only few authors include mooring analysis in their CNWT. A simple mooring representation can be found in [202], where the motion of a spherical PA is constrained to heave and surge through springs with fixed anchoring points. Similarly, Luo et al. [108] implement massless springs in the model of a floating OWC, restraining the body motion to heave only. Ransley et al. [212] also implement a linear spring as mooring representation, however allow body motion in all 6DOF. Verduzco-Zapata and Ocampo-Torres [157] also models a 6DOF WEC where the mooring and PTO system are represented as a rope system. However, details about the mathematical implementation of the mooring system is omitted. More detailed mooring analyses are performed by the authors in [81] and [55] for the OWEL and OPT Power buoy device, respectively, where the CFD solvers are coupled with the mooring analysis software OrcaFlex, however capabilities of the nonlinear mooring analysis tool are not fully exploited. The study in [188] represents the rope connection between the buoy and PTO system through a simple mathematical formulation that does not take any non-linearities of the mooring line (e.g. snap loads) into account. A more sophisticated representation of a mooring line is given in $[82,147]$, which utilises a high-order non-linear Finite Element (FE) solver, so that non-linear mooring forces and snap loads can be captured.

\subsubsection{Control}

In addition to the EMCSs implemented in $[170,171,189,190]$, stroke length control and passive control can be found in [188] and [201], respectively. Dolguntseva et al. [188] includes the stroke control system within the mathematical PTO model by the means of end stop spring forces. In Eskilsson et al. [201], passive control is realised by replicating a pressurized pneumatic cylinder, i.e. air spring, in the numerical model providing a negative spring force on the PTO system.

\subsubsection{Hybrid simulations}

Through the coupling of CNWTs with other numerical solvers, hybrid simulations can be performed, such as the one- or two-way coupled FSI in $[105,174,125,214]$. Here, structural solvers are coupled with CFD, using fluid forces as input only (one-way), or additionally feeding structural displacements back to the CFD solver (two-way). Connecting CFD solvers to a numerical toolbox, such as Matlab, PTO systems [188], sophisticated control algorithms [190] or mooring models [82,147] can be included in the CNWT. Mooring has also be added to the CNWT through specific mooring solvers, such as OrcaFlex $[55,81]$. To reduce the computational burden for large fluid domains, [30,35,168,169] propose coupling low-/mid-fidelity models based on PF with high-fidelity CFD-based models, where the wavefield in the domain far-field is modelled via PF models, while the flow field in vicinity of the WEC is modelled through viscous, non-linear CFD models.

\section{Problem discretisation}

The CFD problem discretisation, in terms of computational mesh (spatial) and time step control (temporal), is one of the key settings to be selected by the user to ensure efficient and accurate simulations. Similar to turbulence modelling (see Section 5), effort has been undertaken in the field of naval architecture and ship hydrodynamics to provide guidelines for the mesh and time step sizes [228-230]. However, the large difference between these classical offshore engineering fields and WECs (e.g. large resonant motions), hinders the immediate use of these guidelines, reflected by the fact that in this review only one WEC in [160] refers to general CFD engineering guidelines. 


\subsection{Convergence}

Appropriate problem discretisation must be determined via convergence studies [231-233]. Various approaches are found in the literature to declare converged discretisation.

Very few studies employ established convergence measures. Only very recently, the authors in $[200,201]$ propose a methodology based upon $[234,235]$ to ensure and/or quantify the uncertainty of CNWT experiments. To highlight potentially misleading results from different convergence studies, the authors use an established four grid method based upon Richardson Interpolation and compare results to simple convergence tests based on relative difference between quantities from different meshes. It is pointed out that more sophisticated approaches to identify grid convergence are needed and should be favoured over simpler quantitative or qualitative (i.e. visual inspection) methods.

Evolving from the enhanced use of CFD engineering in the field of aerodynamics, the study [231] proposes the use of the Grid Convergence Index (GCI) in order to produce comparable and coherent convergence results. For the proposed method, three different grid (mesh) sizes are used to determine the GCI which can prove converged solutions. This method is used by the studies [117] and [173].

Omitting a standardised convergence quantity, such as the GCI, three different levels of fidelity for assessment of convergence can be observed in the reviewed literature:

(i) Providing no information and simply defining the discretisation as converged

(ii) Qualitative assessment by visual inspection of graphs

(iii) Quantitative assessment via the relative change of a certain quantity between the discretisation levels

Categories (i) and (ii) are the most common. Only studies $[31,92,113,211,222]$ provides a quantified convergence assessment, stating difference between tested meshes of $0.5 \%$ to $12 \%$. However, considering $[200,201]$, certainty about grid convergences can not necessarily be assumed.

\subsection{Discretisation quantities}

For CNWT WEC analysis, wave propagation must be resolved with highest accuracy, but in the most efficient way. Hence, convergence studies mainly focus on the discretisation around the free surface. However, when FSI is considered (especially in turbulent conditions), the discretisation around a body must be chosen carefully. Refs. $[18,92,131,142,147,160,177]$ and Refs. [53,92,95,102,116, $159,173,184,186,202]$ provide detail on their body discretisation. Here, the former use the boundary layer thickness in terms of $y^{+}$values (see Section 5) as the quantity of interest, whereas the latter provide mesh sizes normalised by characteristic body dimensions. Nevertheless, quantification of the convergence is omitted in all of theses studies.

Tables 4 and 5 list the publications with convergence studies for the spatial and temporal discretisation, respectively. The spatial discretisation is categorised by the number of cells per waveheight (CPH). The temporal discretisation is categorised by the use of fixed or variable time steps, where the latter is controlled through the Courant Friedrichs

\section{Table 4}

Spatial discretisations determined through convergence studies used in the reviewed literature.

\begin{tabular}{ll}
\hline CPH & Literature \\
\hline $0 \leq C P H \leq 10$ & {$[18,31,58,77,113,114,122]$, chap.5, $[122]$, chap.6 } \\
& {$[99,100,140,141,161,165,173,176,177,191,192,212,213,222]$} \\
$10<$ CPH $\leq 20$ & {$[22-24,31,33,41,49,51,63,92,108,116,122]$, chap. 4} \\
& {$[142,160,166,167,193-199,209]$} \\
CPH $>$ 20 & {$[31,122]$, chap. 7 $[123,134,185]$} \\
\hline
\end{tabular}

Lewy (CFL) condition and the maximum Courant number $\mathrm{Co}_{\max }$. It can be stated that in vicinity of the free surface interface, structured grids with a spatial discretisation of $\mathscr{O}(10 \mathrm{CPH})$ and $\mathcal{O}(100)$ cells per wavelength are most widely applied in the literature. Similarly, $C o_{\max }$ with values of around 0.5 are commonly used.

\section{Flow regime}

The inclusion of viscosity and vorticity in the governing equations, further separates CNWTs from PF models. Regarding the inclusion of viscous effects, different flow regimes can be identified: inviscid, laminar and turbulent. Inviscid flows (see Section 5.1) neglect viscosity and the NSE are reduced to the Euler equations. Including viscosity, but assuming no interaction between adjacent fluid layers, a laminar regime (see Section 5.2) can be considered [7]. Removing this assumption, the flow is treated as turbulent (see Section 5.3), where unstable flows are characterised by $3 \mathrm{D}$ fluctuations in space evolving in time. As will be detailed in this section, solution of the latter flows significantly increases the computational burden, however are likely to be a more realistic representation of the physical problem. To summarise the findings of this section, and to assist CFD engineers select appropriate models for WEC applications, Table 6 lists the different modelling techniques for the different flow regimes with their characteristics and the related studies in the literature.

\subsection{Inviscid flow}

Although CFD, especially for FSI, is usually only considered for applications where simplifying assumptions, such as inviscid flow, do not apply, situations may arise in which neglecting viscosity is useful. For example, to investigate the performance of the large Wave Dragon device, [131] favors inviscid simulations as much as possible, to avoid the requirement of resolving the boundary layers, resulting in a lower mesh count and faster computations.

In a comparative study of CFD techniques, study in [117] employs the AMAZON-3D code, solving the Euler equations. Comparison to viscous flow solvers reveals similar results for cases considering interaction of waves with fixed structures and forced oscillation tests. Investigating the heave response of a structure to extreme waves, similar results between viscous and inviscid flow solvers are found, however neither results align with experimental findings.

Palm et al. [147] employ the Euler equations in a study of a moored PA, to specifically investigate the influence of viscosity. Comparison between turbulent viscous and inviscid flow simulations show discrepancies in the PA dynamics for certain DOFs. For the study on 3D effects on wave excitation forces measured on a horizontal, rigid board, study in [183] compared wave excitation force gained under laminar and inviscid flow. For the studied case of linear and $2^{\text {nd }}$ order waves, no significant influence was found.

\subsection{Laminar flow}

To evaluate the validity of laminar flow assumptions, two dimensionless quantities, the Reynolds number Re (Eq. (1)) and the Keulegan-Carpenter number $K C$ (Eq. (2)), can be employed [236]:

$$
\begin{aligned}
& R e=\frac{u \cdot L}{v} \\
& K C=\frac{u_{m} \cdot T}{L}
\end{aligned}
$$

Here, $u$ describes the characteristic free stream velocity, $L$ the characteristic length, $v$ the kinematic viscosity, $u_{m}$ the amplitude of the oscillating flow velocity and $T$ the (wave) period [5]. Hence, the validity of laminar flow assumption may be dependent on both the sea state (velocities, period) as well as the model scale. 
Table 5

Temporal discretisations used in the reviewed literature.

\begin{tabular}{|c|c|}
\hline Fixed time step & CFL condition \\
\hline$[15,17,22-24,33,41,50,51,53,63,58,66,75,95,108,134,160,162,166,167,178,193-199,211]$ & [122], chap.5, [99,165,186,191,192,209,206,207,212,213,222] \\
\hline
\end{tabular}

Table 6

Turbulence Models and their characteristics used within CNWT for WEC analysis.

\begin{tabular}{|c|c|c|}
\hline Model & Characteristics & Literature \\
\hline Euler & Assuming inviscid flow naturally neglecting any turbulent (viscous) effects & {$[15,17,26,49,66,117,131,147,183]$} \\
\hline Laminar & $\begin{array}{l}\text { Low Reynolds number and small Keulegan-Carpenter number; Considering no } \\
\text { turbulent (viscous) effects }\end{array}$ & $\begin{array}{l}{[26,65,72,84,89,95,99,122,123,147,160,161,165,170,171,173,176,17-} \\
8,191,210,215]\end{array}$ \\
\hline$k-\varepsilon$ & $\begin{array}{l}\text { Computationally cheapest; poor accuracy in near wall regions; good accuracy } \\
\text { in far wall regions }\end{array}$ & $\begin{array}{l}{[18,22-24,33,38,40-42,46,51,53,57,58,60,63,64,67,76,82,88,93,96,1-} \\
06-109,116,118,134,142,154,224,159,163,185,186,211,222]\end{array}$ \\
\hline $\begin{array}{l}\text { Realisable } \\
\quad k-\varepsilon\end{array}$ & Simpler, more robust and physical model of $\varepsilon$ transport equation; & {$[143,224,209]$} \\
\hline RNG & $\begin{array}{l}\text { Consideration of different length scales in } \varepsilon \text { transport equation; explicit } \\
\text { formulation of the model constants; inherent consideration of low Re flows; } \\
\text { well suited for rapidly strained flows }[244,245]\end{array}$ & {$[8,16,28,29,120,121,131,132,147,224,176,177,200,220,221]$} \\
\hline$k-\omega$ & $\begin{array}{l}\text { Similar definition of transport equations; turbulent length scale as function of } \\
\text { turbulent frequency } \omega \text {; good accuracy in near wall region; poor accuracy in far } \\
\text { field due to high sensitivity to (assumed) far field values of } \omega\end{array}$ & {$[94,140,141,178,215]$} \\
\hline$k-\omega \mathrm{SST}$ & $\begin{array}{l}\text { blended model of } k-\varepsilon \text { and } k-\omega \text {; good accuracy in near wall boundary layer } \\
\text { (due to } k-\omega \text { ) and far wall regions (due to } k-\varepsilon \text { ) }\end{array}$ & $\begin{array}{l}{[54,55,77,86,92,97,125,138,139,152,153,162,166,167,180,188,193-1-} \\
99,201,206,207,214]\end{array}$ \\
\hline LES & $\begin{array}{l}\text { Computationally costly, accurate resolution of turbulent effects up to a defined } \\
\text { length scale, particularly suitable for simulations including unsteady } \\
\text { separation and vortex shedding [237] }\end{array}$ & {$[110,153,217-219]$} \\
\hline
\end{tabular}

In their study on a submerged cylindrical WEC, study in [95] assumes laminar flow conditions based on $R e<1 \cdot 10^{4}$ and $K C<1.0$. For the simulation of a heaving buoy WEC considering latching control, $[170,171]$ finds $R e \approx 2 \cdot 10^{4}$ and hence assume laminar flow. Furthermore [165] justifies the laminar flow assumption for a single floating point absorber with low KC numbers and finds underpinning agreement to experimental data. In [99,123,161] (all combined in [122]), little effects due to turbulence are assumed for the tested horizontal fixed cylinder, rolling barge and flap type WECs. More so, negative effects associated with the empirical nature of turbulence models (see Section 5.5.1 - 5.5.4) are identified. Lastly, the reduced computational cost for laminar flow simulations is highlighted.

In a wave-only study [84] expects no influence from turbulence due to the absence of a solid structure in the flow. The validity of laminar flow in wave-only studies is also indicated in [85] and [122]. Comparing results of surface elevation, study in [122] highlights negligible turbulent effects when comparing laminar results with the $k-\omega$ turbulence model (see Section 5.5.4) for a single sea state only. Again, studying wave-only cases, [58] and [134] compared results under laminar assumption with results gained using turbulence models $(k-\varepsilon$, $k-\omega \mathrm{SST}$ ), finding no significant difference. A comparison between laminar flow conditions and the RNG $k-\varepsilon$ model (see Section 5.5.3) is undertaken in [176] for 2- and 3D tests on a flap type WEC, where reasonable agreement between laminar 2D and RNG 3D test cases is found. In a study on extreme waves and FSI on a vertical cylinder, [173] considers laminar flow conditions, stating that no wave breaking, hence insignificant effects due to turbulence, is expected. Furthermore, the Re is kept low $(R e=975)$ throughout the study. The authors in [178] assumes laminar flow, studying force coefficients on horizontal and vertical plates, justified by $R e$ in the range of $5000-10000$. Lastly, $[191,192]$ assumes laminar flow condition justified by low $K C$ numbers in all simulations.

These studies highlight the validity of laminar flow assumptions for a number of cases. However, using laminar flow must be assessed on a case by case basis, either driven by hydrodynamic boundary conditions ( $R e$ or $K C$ ), presence of FSI or the mere reduction of computational cost.

\subsection{Turbulent flow}

To account for turbulent flow conditions, various methodologies have been developed, which can be distinguished by their computational cost and accuracy. Most accurately, turbulent fluctuations and stresses are captured by Direct Numerical Simulations (DNS). Providing solutions for small scale and high frequency turbulent effects, the NSE must be solved with fine temporal and spatial discretisations. Temporal discretisation must be able to capture the period of the fastest turbulent fluctuation, spatial discretisation must be fine enough to resolve the Kolmogorov length scale (scale at which inertia and viscous effects are of equal strength [7]). Such fine scale discretisations greatly increase the computational burden, making DNS infeasible for practical applications. In the reviewed literature, no application of DNS for WECs is found.

Lower fidelity solutions, with lighter computational requirements, are obtained by modelling the fine scale turbulent effects, as is the case for Large Eddy Simulations (LES) and the RANS approaches, detailed in Sections 5.4 and 5.5, respectively.

\subsection{Large Eddy Simulation (LES)}

To avoid discretisation down to the Kolmogorov length scale, LES only directly accounts for larger turbulent eddies. The effects of smaller scale eddies are modelled instead, using a sub-grid-scale (SGS) model. Although this procedure comes at a lower computational cost than DNS, LES is still significantly more costly than RANS turbulence models. Prior to the solution of the governing equations, spatial filtering decomposes the velocities into resolved and residual components based on the SGS. Resolved velocity components are directly accounted for, whereas the system of equations for the residual turbulent stresses is closed by the underlying model. For a more detailed insight, the interested reader is referred to [237] and [238].

For WECs, LES is currently only employed in the consecutive studies on OWCs [110,153,217-219]. Simonetti et al. [153] provide a comparative study between the $k-\omega$ SST model and LES. Better agreement 
between experimental results and numerical simulations are found for LES than the $k-\omega$ SST model, at a higher computational price.

\subsection{Reynolds Averaged Navier Stokes (RANS)}

With reasonable computational cost and accuracy in practical applications, the most common method to account for turbulent effects are turbulence models, based on the RANS equations (RANSE). Considering turbulent effects as 3D fluctuations of flow quantities, the Reynolds decomposition splits the flow quantities into a time-averaged and fluctuating components, leading to the RANSE. Special attention needs to be paid to additional turbulent stresses (Reynolds stresses), which stem from the time averaged velocity fluctuations and physically represent shear stresses between accelerated and decelerated fluid layers due to momentum exchange [7]. The addition of extra terms in the RANSE requires extra equations to be added to achieve closure. The extra equations come in the form of turbulence models, described in Sections 5.5.1-5.5.5.

\subsection{1. $k-\varepsilon$ model}

The two-equation $k-\varepsilon$ turbulence model, developed by [239], is the most prominent and widely validated turbulence model. Introducing two new transport equations for the kinetic turbulent energy $(k)$ and the dissipation rate of kinetic energy $(\varepsilon)$, closure of the RANSE is achieved.

In the standard $k-\varepsilon$ (SKE) model, transport equations for $k$ and $\varepsilon$ feature the eddy viscosity, as well as adjustable model constants. Standard values for the constants are found from empirical data fitting [7]. In the reviewed literature, almost all studies employing the SKE model use the standard model constants. Only $[76,93,186]$ do not provide information concerning the implemented constants.

The $k-\varepsilon$ model has mainly been applied for the simulation of OWCs $\quad[18,22,24,33,38,41,51,63,64,76,79,93,96,104,106-108,118$, $159,186,222]$. The application in the different studies range from performance analysis [18,118,159,222], (structural) optimisation $[76,186]$, to SI [96]. However, none of the studies disclose a reasoning for their choice of turbulence model.

Studying drag effects on the M4 WEC, the authors in [154] compare the standard $k-\varepsilon, k-\omega$ SST (see Section 5.5.5) and the adopted $k-\varepsilon$ V2F [240] models against experimental data and laminar flow simulations. From the results of free-decay experiments it is stated that $k-\omega \mathrm{SST}$ and $k-\varepsilon \mathrm{V} 2 \mathrm{~F}$ give similar results, whereas the $k-\varepsilon$ and laminar flow models overestimate the oscillation amplitude. The authors select the $k-\varepsilon$ V2F model for subsequent studies. In the study of viscous effects for an OWSC, [224] presents comparative results considering the SKE, RNG (see Section 5.5.3), realisable $k-\epsilon$ (see Section 5.5.2) and $k-\omega$ SST model. Finding negligible differences between the results, the reduced computational costs for the SKE model lead to its implementation in the remainder of [224].

\subsubsection{Realisable $k-\varepsilon$ model}

Shih et al. [241] specifies the potential lack of accuracy of the SKE, due to the overprediction of turbulent eddy viscosity and false turbulent length scales. To tackle this problem, the authors propose a new model for the $\varepsilon$ transport equation and the eddy viscosity, that is simpler, more robust and physically realistic. This is achieved by introducing a nonconstant variable $C_{\mu}$ in the eddy viscosity equation. The definition of the new eddy viscosity influences the calibration of the model constants for the refined $\varepsilon$ transport equation, and suggested values are presented in [242]. As mentioned in 5.5.1, [224] presents a comparison study finding negligible differences between the results of the realisable $k-\varepsilon$ and other turbulence models.

\subsection{3. $R N G k-\varepsilon$ model}

Another refined turbulence model based on the SKE was developed by [243] applying the Re-Normalisation Group (RNG) method. RNG allows the consideration of different turbulent length scales within a modified $\varepsilon$ equation [244]. This modification introduces two new model constants $\left(\eta_{0}, \beta\right)[244,245]$ and, moreover, allows the explicit, rather than empirical, determination of the unknown constants. Compared to the SKE model, the RNG $k-\varepsilon$ approach generally achieves improved accuracy due to this explicit formulation and the inherent consideration of low Re flows.

In the reviewed literature, the RNG model has been applied for a number of WECs, such as overtopping [121], PA [28,120,147] and OWSC [176]. Applications range from extreme load estimation [121], model validation $[28,29,147,176]$ to the assessment of viscous drag effects [120]. Loh et al. [176] presents results comparing the laminar flow assumption and RNG turbulence modelling, revealing slightly better fitting results (to experimental data) for the case of turbulence modelling. In a study on the FSI of a floating body, Li and Yu [8] compare the RNG and standard $k-\varepsilon$ model to experimental results, finding that the former yields better agreement in the force data. Bhinder et al. [28] provides justification for the applied model by stating it is the preferred model for the employed CFD software Flow3D. [16] differs from the aforementioned studies by presenting a coupling strategy for time domain potential flow and fully non-linear CFD solvers for wave-only cases. However, no reasoning for the choice of the RNG turbulence model is given.

\subsection{4. $k-\omega$ model}

In the SKE model, the turbulent length scale, $\ell$, for the definition of the turbulent eddy viscosity, is a function of the rate of dissipation of turbulent kinetic energy. Another definition of this turbulent length scale stems from the turbulent frequency $\omega=\frac{\varepsilon}{k}$. This definition is used in the (Wilcox) $k-\omega$ model developed by [246-249].

Transport equations for $k$ and $\omega$ can be formulated, and a set of adjustable constants must be defined [7]. Benefits for the $k-\omega$ model are found in the treatment of near wall boundary layer flows compared to the SKE model. However, accuracy issues may occur in the free stream due to solution sensitivity to the (assumed) initial value of $\omega$ in the far wall region. In the reviewed literature, few authors are found to apply the $k-\omega$ model, i.e. $[94,140,141,178]$, but no reasoning for the selection of the turbulence model is given. Only [215] provides a rather qualitative comparison between turbulent and laminar assumptions, concluding that the necessity of modelling turbulent effects has to be assessed on a case by case basis.

\subsection{5. $k-\omega S S T$ model}

While the SKE model achieves accurate modelling of fully turbulent far wall regions and the Wilcox $k-\omega$ model is accurate for the nearwall boundary layers, the $k-\omega$ shear stress transport (SST) model, proposed by Menter [250], blends the SKE (in far wall regions) and $k-\omega$ (in near wall regions) to achieve accurate modelling for both regions.

In addition to the aforementioned comparative study in [224], the $k-\omega$ SST model is also compared against LES in [153], for the case of an OWC, where better agreement with experiments are found for LES. Comparing $k-\omega$ SST to LES, deviations up to $10 \%$ for the FSE and $13 \%$ for the pressure inside the OWC chamber, and 13\% for the velocity in the pipe are found, with a $15 \%$ greater computational cost for LES. Studying fixed OWCs, study in [167] compares $k-\varepsilon$, realisable $k-\varepsilon$ and $k-\omega$ SST models, where the $k-\omega$ SST model is shown to give the best results.

\section{Wave generation and absorption}

CNWT WEC experiments rely on accurate wave generation and absorption at the NWT boundaries, which can be provided by various numerical wave maker (NWM) methods, as depicted in Fig. 4. Following [251], the different NWM methods can be categorised as: relaxation, static boundary, dynamic boundary, mass source, impulse 
Wave Generation

(a)

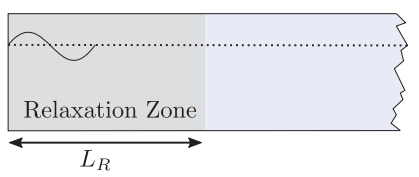

(b)

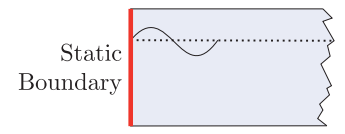

(c)

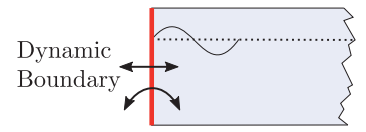

(d)

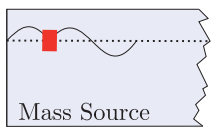

(e)

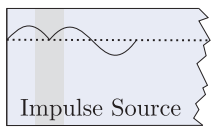

Wave Absorption

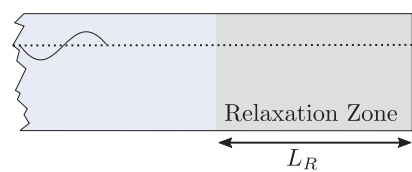

(g)

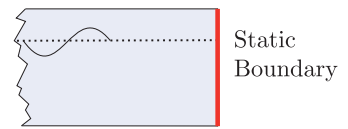

(h)

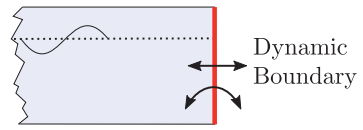

(i)

(i)

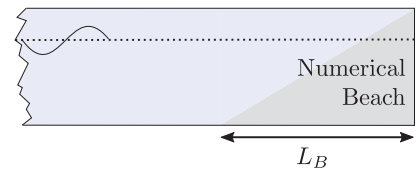

(j)

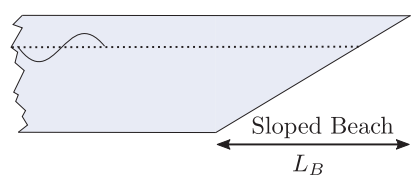

(k)

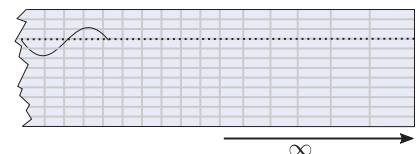

Fig. 4. Schematic representation of available wave generation (a) - (e) and absorption methods (f) - (k) (Figure adapted from [251]).

source and numerical beach methods. Section 6.1 reviews the wave generation methods, and then wave absorption are considered in Section 6.2. The reviewed literature is categorised in Table 7 using the different NWM methods.

\subsection{Wave Generation}

The NWM is responsible for creating the input waves in a CNWT simulation. An ideal NWM should be able to produce a variety of wave fields:

- Deep and shallow water waves

- Monochromatic and polychromatic sea states

- Reproduction of arbitrary FSE time series, measured from a physical wave tank or ocean test site
Typically, there exists a minimum distance from the NWM within which testing should not be undertaken, where evanescent waves occur and the waves are not yet fully developed. Furthermore, the presence of bodies in the CNWT cause wave reflection/radiation travelling away from the bodies back to the wave generator, which the NWM control must account for when generating the desired wave field. In the following subsections, the different wave generating NWM methods are discussed.

\subsubsection{Relaxation method}

The relaxation zone method generates waves by relaxing a target solution, $\phi_{\text {target }}$, for FSE and velocities into the calculated solution, $\phi_{\text {computed }}$ (see [252] and [253]). A relaxation function is defined inside the relaxation zone, so that the quantity $\phi$ (FSE or velocity) follows:

Table 7

Numerical wave generation and absorption.

\begin{tabular}{|c|c|c|}
\hline NWM & Generation & Absorption \\
\hline Relaxation & $\begin{array}{l}{[62,69,82-84,89,94,110,119,123,124,130-132,140,145,141,144,151,153,-} \\
170,171,173,176-178,200,201,212,213,217-222]\end{array}$ & $\begin{array}{l}{[62,82-84,89,94,119,110,124,131,132,142,143,145,147,151,153,158,17-} \\
0,171,173,176-178,200,201,205,212,213,217-221]\end{array}$ \\
\hline Static Boundary & $\begin{array}{l}{[8,16,28,29,31,32,37,49,52,52,40,54,55,92,73,74,72,136,112-114,70,87,7-} \\
6,186,79,104,88,38,100,99,161,107,107,117,118,120,121,125,128,134,13- \\
8,157-160,162,169,166,167,183,185,188,191-196,198,197,199,209,206]\end{array}$ & {$[32,49,79,104,128,138,157,165,169,191,192,206,221]$} \\
\hline Dynamic Boundary & $\begin{array}{l}{[15,17,21-24,31,33,41,51,63,60,43,50,53,58,66,75,95,91,90,224,93,46,42-} \\
, 67,109,57,96,102,202,116,184,155,153,210,211]\end{array}$ & {$[22-24,33,41,51,60,63,96]$} \\
\hline Mass Source & {$[18,26,36,64,106]$} & \\
\hline Impulse Source & {$[85,86,97,103,152,180,216]$} & \\
\hline Numerical Beach & & $\begin{array}{l}{[18,26,36,40,8,52,72,54,55,92,69,85,97,103,75,95,100,99,122,161,102,-} \\
108,116,162,166,167,183-185,188,193-196,198,199,197,210,202,209,- \\
214,221,224]\end{array}$ \\
\hline Passive Absorption & & $\begin{array}{l}{[21,28,29,37,52,117,42,67,57,46,58,59,70,87,73,74,76,77,88,38,22,24,3-} \\
3,41,51,63,93,106,109,118,120,121,125,136,140,141,155,159,160,178,- \\
186,211,222]\end{array}$ \\
\hline
\end{tabular}


$\phi=\alpha_{R} \phi_{\text {computed }}+\left(1-\alpha_{R}\right) \phi_{\text {target }}$

where $\alpha_{R}=0$ at the inlet boundary, $\alpha_{R}=1$ at the relaxation/simulation zone interface, and increases smoothly in between. $\phi_{\text {target }}$ is determined from wave theory.

By virtue of the relaxation procedure, any reflected or radiated waves travelling back towards the wave generation zone are inherently accounted for [85]. Nonetheless, [222] found biased results in terms of efficiency for an OWC caused by re-reflection of waves at the relaxation zone. To avoid such re-reflection, the relaxation zone length $L_{R}$ can be increased, at additional computation cost. As guideline for the choice of the relaxation zone length $L_{R}$, a length of $1-2 \lambda$ can be extracted from the reviewed literature.

For simulation of extreme waves, a number of studies apply the NewWave method within the relaxation zone framework $[83,84,89,151,173,212]$. Using this approach, an extreme wave can be reproduced at a specific point in time and space by superposition of linear waves of different frequencies and phases [254]. A detailed description of the representation, implementation and validation of the NewWave methods within the relaxation zone framework can be found in [150], Chap. 4. Generally, an underestimation of the extreme wave trough and overestimation of crest is found during validation studies.

\subsubsection{Static boundary method}

The static boundary method defines the velocity field and the FSE as Dirichlet boundary conditions at the NWM boundary. Waves reflected / radiated towards the NWM are directly considered by imposing flow quantities at the boundary. The exact implementation of this method, and its capabilities (e.g. implementation of different wave theories, reproduction of time series data), are code dependent. For example, authors in [255,256], chap. 5.3 illustrate the implementation for the open-source solver OpenFOAM.

Uniquely, the authors in [158] employ the static boundary method in a circular NWT for the study of wave impacts on an OWSC. The use of a circular domain is justified by the reduction of the overall domain size and hence computational cost. It is shown that the numerically generated waves overestimate the amplitude compared to the analytical input wave characteristics. [134] presents a comprehensive study on irregular wave generation using the static boundary method, adopting the CNWT used by the same author for dynamic boundary wave generation [58]. Agreement between analytical approximation and CFD results is quantified by the coefficient of determination $R^{2}$, found to be 80, 88.1 and 92.2 for the three wave data sets tested. Authors in [162] induce waves and current in the CNWT using the static boundary method, however no validation is given.

\subsubsection{Dynamic boundary method}

The dynamic boundary method directly replicates a physical wave tank, by mimicking the flap/paddle type wavemaker with a dynamically moving boundary wall in the NWT. Higuera et al. [255] find that the dynamic mesh motion introduces an increase in computational effort by about $20-40 \%$ compared to the static boundary method.

Studying the slamming event on an OWSC, authors in $[116,184]$ justify the use of a moving wall wavemakers with the aim of reproducing the setup of the physical experiments as closely as possible. Results show satisfactory agreement between numerical and experimental results of FSE and OWSC motion. Simonetti et al. [153] perform a comparison study between the relaxation zone method and moving wall piston type wave generator simulating monochromatic $2^{\text {nd }}$ order Stokes waves. Results from numerical simulations are validated against experimental data revealing deviations of $\leq 8 \%$ for a piston type dynamic boundary and $\leq 9 \%$ for the relaxation zone method. However, run time comparison $(6 \mathrm{~h}$ for dynamic boundaries versus $2 \mathrm{~h}$ for relaxation method) drive the decision towards using the relaxation zone method for the remainder of the study. Finnegan and Goggins [58] develop a dynamic boundary flap-type wavemaker, for the commercial CFD software Ansys CFX, in a comprehensive study on the generation of regular waves. Results indicate that the wavemaker hinged at the bottom does not compare well with wavemaker theory in deep water, however, comparing to linear wave theory, satisfying results are achieved. Puolakka and Mikkola [66] study the radiation moment on a vertical bottom-hinged flap (used as wavemaker), with the desire of capturing evanescent waves in vicinity of the wavemaker.

While the above mentioned references rely on mesh distortion and remeshing of the domain, authors in [75] propose a dynamic boundary wave generator employing the fast-fictitious-domain method (see Section 7.1.4). In the study, both piston and flap type wave generator are considered, consistently finding good agreement for small steepness waves $\left(\frac{H}{\lambda}=0.009-0.02\right)$ and considerable deviations for higher steepness waves $\left(\frac{H}{\lambda}=0.04-0.06\right)$. The developed wave generator is subsequently used in study [95] to investigate the wave energy absorption efficiency of a generic circular WEC.

\subsubsection{Mass Source Method}

The mass source method [257] displaces the free surface with a (mass) in- and outflow. A source term is defined coupling the surface elevation, wave celerity and the surface area of the source, enabling wave generation through a velocity field boundary condition or a volume source term included in the RANS continuity equation. Since the source term does not alter waves travelling through the source, wave absorption can only be achieved through an additional beach (see Section 6.2.4). Note that with the mass source method, waves get generated in all directions.

In an early work, authors in [18] used the mass source method in a study on OWC devices, considering $2^{\text {nd }}$ and $3^{\text {rd }}$ order Stokes waves. Although no quantitative evaluation of the NWM is provided, surface elevation plots reveal inaccuracies in the wave height. Victor et al. $[26,36]$ apply the mass source method to generate monochromatic waves in intermediate water depth. Lopez et al. $[64,106]$ aim on the generation of monochromatic and polychromatic waves in intermediate water depths. None of the above studies provides information on the quality or efficiency of the mass source method.

\subsubsection{Impulse Source Method}

The impulse source method, proposed by authors in [258], extends the idea of the mass source method, whereby a source term is added to the momentum equation, coupling the fluid density and an analytical solution of the wave velocity for each cell within the wavemaker region. Again, wave absorption can only be achieved through an additional beach. The source term in [258] can be calculated analytically for shallow water waves only. However, study [85] provided a method, based on spectral calibration used in physical wave tanks, to allow the source term to be calculated in any water depth, although with the disadvantage of requiring several simulations for the iterative calibration procedure, which can prove computationally costly. This method was then used by the same author in the consecutive studies of OWSCs $[86,97,103,152,180,216]$.

\subsection{Wave absorption}

The NWM must be able to absorb outgoing waves, so that wave reflection is eliminated, or at least significantly mitigated, and does not corrupt the CNWT experiment. Wave absorption methods can be classified as active or passive, where active methods include the static/ dynamic boundary method, relaxation zone method or the implementation of a numerical beach (damping source terms, increasing viscosity, etc.). Passive wave absorption here refers to artificial wave dissipation achieved by stretching the cells in the vicinity of the FFB or including a geometrical beach, i.e. slope, in the domain. 


\subsubsection{Relaxation method}

Employing the relaxation method for the wave absorption, the procedure follows the description in Section 6.1.1. However, now the target solution (i.e. zero velocity, zero FSE from still water level (SWL)) is enhanced towards the FFB by definition of $\alpha_{R}$.

Special attention should be paid to the studies [158] and [143], employing the relaxation method on circular NWTs. As stated in [158], the implementation of a circular domain "greatly" reduces its size. In [143], radiation tests on the WaveBob are performed. The cylindrical shape of the device here suggests the use of a circular domain to most efficiently avoid wave reflection from the boundaries.

If the relaxation zone method for wave absorption is employed in a square NWT, a length of $1-4 \lambda$ can be extracted from the reviewed literature as guideline for the choice of the relaxation zone length $L_{R}$.

\subsubsection{Static boundary method}

Like in the wave generation case, the velocities and FSE data are set as Dirichlet BCs in the static boundary method. However, determining the necessary values for the velocity field requires more attention to effectively absorb waves. For example, in the implementation proposed by the authors [255, chap. 5.3] and [256], a correction velocity $U_{c}$ is applied at the boundary based on shallow water theory (i.e. constant velocity profile along the water column).

In the reviewed literature only a few researchers, i.e. $[32,49,79,104,128,138,157,165,169,191,192]$, employ a static boundary at the FFB. Specifically $[79,104,128,138,165,169,191,192]$ use the proposed method by authors in [256] and [255, chap. 5.3]. In $[32,49]$, the CFD code AMAZON-SC 3D allows the definition of a nonreflective boundary. Unfortunately, further information on characteristics or the implementation of this boundary are not given. Using the Sommerfeld radiation condition, authors in [157] induces fluid velocities in order to dampen incident waves. Finally, it can be stated, that none of the above mentioned studies provides quantification of the absorption quality.

\subsubsection{Dynamic boundary method}

Like in the wave generation case, the dynamic boundary method replicates the piston/paddle wave absorbers in real wave tanks. The control of the wave absorber is therefore of crucial importance to achieve accurate absorption.

In the reviewed literature [96] and the consecutive studies $[22-24,33,41,51,60,63]$ have been found, employing the dynamic boundary method for wave absorption. In [96] outputs from 2D CFD simulations on a generic OWC are used in order to identify state-space coefficients for the solution of the Cummins equation, considering data from CNWT free decay experiments, as well as monochromatic (linear) and polychromatic (linear and non-linear) sea states. In their discussion, no evidence of issues related to the wave absorption can be found. However, surface elevation data outside of the OWC chamber are not shown, so that no conclusions on the absorption quality can be drawn. Authors in [22-24,33,41,51,60,63] implement dynamic boundary wave absorption through the Sommerfeld radiation condition [259]. Giving a relation between FSE and horizontal velocity component, the moving wall at the absorption boundary can be driven accordingly. Again, no evaluation of the accuracy and efficiency is provided.

\subsubsection{Numerical beach implementation}

Numerical beaches can dissipate incident waves by the following methods found in the reviewed literature:

- Increasing the viscosity of the liquid phase with distance in a region towards the FFB

- Addition of a sponge layer to force velocity and/or FSE to be zero

- Addition of a damping term in the momentum equation causing energy dissipation
For the sake of brevity, in-depth descriptions should be extracted from the references listed in Table 7. However, it should be pointed out here, that the consecutive studies $[99,100,122,161]$ as well as $[69,85,97,103,180,216]$ refer to quantified absorption efficiency in terms of the reflection coefficient in the order of $<2 \%$.

To achieve low reflection coefficients (or high absorption efficiency), authors use beach lengths in the order of $1-5 \lambda$, which is similar to the relaxation zone length.

\subsubsection{Passive absorption}

While the aforementioned wave absorption methods can be categorised as active wave absorption, i.e. influencing the numerical solution in a region/boundary of the CNWT, a sloped bathymetry or cell stretching can be categorised as passive wave absorption.

Implementing a slope at the CNWT FFB dissipates wave energy, replicating the effect of beaches in the physical world. With the cell stretching method, the spatial discretisation is gradually enlarged towards the FFB and any wavelengths shorter than the cell size are filtered out. This requires rather long domains to reach cell sizes which are able to absorb waves used in practical applications. However, cell stretching is often used to supplement active wave absorption methods and also reduce the number of required cells in a given absorption domain length. Study [106] includes a geometrical beach upstream of a mass source NWM.Chen et al. [125] and Scarpetta et al. [155] employ a geometrical beach for the study of the REWEC1 submerged OWC and a Wavestar like PA, respectively. Investigating different slopes for geometric beaches, ranging from 1: 3 to $1: 6$, [58] finds best absorption performance for a 1: 5 slope.

\section{Fluid-structure interaction}

Implementing FSI for WECs in CNWTs requires two main components: the WEC body must be included in the CNWT, and the resulting WEC body motion must be calculated and implemented. Including a WEC body into the CNWT mesh can be achieved by various body representation methods (BRM) and is discussed in Section 7.1. Implementing body motion requires calculation of forces, solution of system dynamics and adaption of the computational mesh, and is detailed in Section 7.2.

\subsection{Body representation methods}

A good overview of the most prominent BRM, is given in $[117,260,261]$. The different BRM vary in terms of: initial setup complexity, handling of dynamic mesh adaption, computational accuracy and efficiency. In some cases, the BRM is intrinsic to the CFD software, and must be considered when choosing the CFD software for a particular problem. In the following, the different BRM used in the reviewed literature are briefly discussed and tabulated in Table 8, however for brevity, the standard body fitted methods (Section 7.1.1) are excluded from this table.

Table 8

Body representation methods (excluding standard body fitted method) used within CNWT for WEC analysis.

\begin{tabular}{ll}
\hline BRM & References \\
\hline Body Fitted: Remeshing & {$[22-24,33,41,51,60,63,81,90,91,116,224,184,188]$} \\
Body Fitted: Multibody & {$[54,55,92,142,162]$} \\
Body Fitted: AMI & {$[68,69,74,77,81,85,86,94,97,103,119,152,169,176,-$} \\
& $180,216]$ \\
Cartesian Cut Cell & {$[15,17,19,32,37,39,45,49,72,73,117,140,141,146]$} \\
Overset Grids & {$[154,160,163]$} \\
Fast-Fictitious-Domain & {$[75,95,102,202]$} \\
FAVOR & {$[25-29,36,120,157,210]$} \\
\hline
\end{tabular}




\subsubsection{Body fitted}

By far the most widely applied BRM is the body or boundary fitted approach. As stated in $[260,261]$, this method requires considerable effort to ensure sufficient mesh quality throughout the domain. Dependent on the CFD and/or meshing software, either (block-) structured or un-structured grids can be used. The most severe limitation is the handling of dynamic mesh adaption $[260,117]$.

In the case of fixed mesh connectivity, body motion can only be handled by mesh distortion, where the displacement is diffused into the domain. This procedure is computationally efficient, but can potentially introduces numerical errors due to poor mesh quality (highly skewed cells). Hence, mostly small, sDOF motions are considered when using this method. However, studies in [54,55,92,142] and [162] employ it on a multibody system, representing the OPT Power Buoy and a twinraft, respectively.

If mesh connectivity is not fixed, remeshing can be applied. Compared to mesh distortion, remeshing allows larger body displacements, but significantly increases the computational burden and potentially introduces numerical errors to the solution. In the reviewed literature only [188] and the consecutive studies [90,91,116,224,184] as well as $[22-24,33,41,51,63,60]$ employ remeshing.

Arbitrary mesh interfaces (AMIs), provide sliding interfaces between mesh blocks, allowing large displacements, without distorting or remeshing the computational domain. Problems however can occur during interpolation of the solution across the mesh interfaces. Studies in $[68,97,103,69,85,86,152,180]$ apply the AMI to cater for the large rotational angles of the flap type OWSC, Oyster. Nicholls-Lee et al. [81] extend the AMI, including mesh distortion and remeshing, to model the floating OWC OWEL, where pitching motion is captured through rotation of a horizontal cylindrical mesh block surrounding the body, and translational motion is accounted for by mesh distortion and remeshing. Devolder et al. [191,192] use the AMI to simulate an array of heaving WECs, where vertical cylindrical mesh blocks surrounding the WECs sliding vertically relative to each other.

\subsubsection{Cartesian cut cell}

To avoid complex and time consuming grid generation, as well as reducing numerical errors, Causon et al. [260] propose the use of the Cartesian cut-cell (also known as immersed boundary) method for multiphase flow calculations. In this approach, the body is cut out of the (Cartesian) background mesh leaving partially cut cells, specially treated in the numerical method. Body motion is handled by simply repeating the cutting procedure with the new boundary positions. In the reviewed literature, the pioneer studies on rotating vanes $[15,17]$ are found to employ the cut-cell BRM. Furthermore, the cut cell method, as applied in $[32,39,49]$ for the analysis of floating bodies in extreme waves, is considered in the code comparison studies by $[37,72,117]$. Studies in $[45,73,140,141]$ employ the cut cell method for studying fixed OWCs, while the study in [146] considers the generic multi-body WEC of the OMAE hydrodynamic modelling competition [262]. Lastly, the CNWT developed by Greaves [19] is based upon the Cartesian cut cell method. The comparably limited number of studies considering the cut-cell method can possibly be reasoned by the limited accessibility of CFD softwares providing this BRM: the in-house code, AMAZON, and the commercial software, Flow-3D.

\subsubsection{Overset Grids}

Focusing on handling large body motions, Benek et al. [263] propose using two overlaid meshes, referred to as the overset grid or
Chimera method. Here, the two meshes are internally static with fixed mesh connectivity, however can move relative to each other. Interpolation between meshes is then needed to transfer solutions. This interpolation is computationally costly, nevertheless large body displacements can be handled without changing mesh topology. In the reviewed literature, only $[154,160,163,185,198,199]$ employ the overset grid method, as implemented in the commercial CFD software, Star-CCM +.

\subsubsection{Fast-fictitious-domain}

A rather unique BRM can be identified from [95,75,102,202], employing the fast-fictitious-domain method, proposed by Sharma and Patankar [264]. In this method, the governing equations are solved throughout the whole computational domain, however, bodies are represented as solid zones attributed with high values of viscosity. This representation allows for arbitrary, large amplitude body motion, avoiding any mesh distortion, remeshing or solution interpolation.

\subsubsection{Fractional Area-Volume Obstacle Representation}

The Fractional Area-Volume Obstacle Representation (FAVOR) technique represents the body by using fractional cell volumes and areas on cell sides, in a similar manner to the volume of fluid method for tracking the FSE, allowing the body to pass through a stationary mesh. Hence, any form of remeshing or mesh distortion is omitted in this technique. For more details see [265]. The FAVOR method is proprietary to the commercial CFD software, Flow-3D, so only a limited number of studies within the reviewed literature, with access to the Flow-3D software, employed this BRM [25-29,36,120,157,210].

\subsection{Body motion}

For a fixed structure, the body is simply regarded as solid boundary (wall) in the CFD domain. However, for a dynamical system, the body motion due to interaction between the fluid and WEC subsystems, must be calculated and then implemented in the CFD domain (via dynamic mesh adaption). This process is performed by the motion solver (see Fig. 5). Within a time step or solver iteration, the motion solver performs the following steps (i) update position, (ii) calculate forces, (iii) update acceleration, (iv) move object and finally (v) move mesh.

The hydrodynamic forces on the body is composed of the pressure and shear forces from the fluid. The pressure force is obtained by integration of the calculated fluid pressure over the surface area of the body. Likewise, the shear force is obtained by integrating the shear, due to the fluid viscosity and the relative body-fluid motion. Additional forces may be applied to the body due to the PTO, mooring or multiple interconnected bodies.

Coupling between the fluid and motion solvers is required to ensure equilibrium of the body with the fluid. Achieving stable simulations is heavily dependent on the implementation of the motion solver within the numerical process, time step control and potentially user defined parameters. A comprehensive review of the (implicit) motion solver used within the CFD software OpenFOAM is given in [128], and stability issues with the motion solver implementation are highlighted and improvements suggested.

There are two options for implementing experiments with body motion; either prescribed or solved motion:

- Prescribed Motion: involves updating the body motion along a predefined trajectory, irrespective of the forces acting upon it.

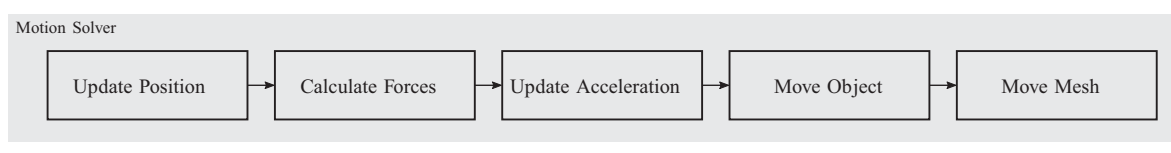


Prescribed motion tests are generally useful for SI purposes [179], where the motion of the body is the input and the resulting hydrodynamic force measured on the body is the output. These tests can be used to identify the hydrostatic restoring force as a function of body position $[101,135]$, or the radiation and/or viscous forces on the body due to its velocity [56,77,143,151,203,207].

- Solved Motion: involves calculating the body's trajectory from the forces acting upon it, via Newton's 2nd law of motion. The motion can be constrained to specific DOFs by the motion solver if required.

For solved motion, the motion may result from an initial displacement from equilibrium (free decay test), or due to excitation from input waves or external forces:

- Free Decay Tests: are a simple example of body motion, whereby the body is initially displaced from equilibrium (either non-zero position or velocity) and the resulting motion simulated as the body oscillates back to its rest position. Free decay experiments are commonly used for SI purposes, such as for the analysis of viscous drag effects $[28,43,54,92,95,97,147,154,161,202]$, identification of the WEC state dynamics $[78,96,126]$, and identification of the WEC resonant period $[149,164,189]$. Free decay tests have also been used to assess NWM wave absorption ability by detecting the influence of reflected waves on the free decay body motion [223].

- Wave Induced Motion: is obviously a crucial element of a CNWT for WEC applications. The variations in FSE and fluid pressure around the body, due to incident waves, results in excitation forces on the body, from which body motion is calculated by the motion solver. Examples of wave induced motion can be found in the majority of the reviewed literature.

- External Forces: from the WEC subsystems may be incorporated into the motion solver. Examples can be found in the literature discussed in Section 3.2 [82,105,147,170,174,188-190]. Input forces have also been used for SI purposes, identifying models between input forces and body motion $[149,172]$. A discussion on the input force characteristics for efficient model identification is given in [164].

\section{Validation methodologies}

It is well-known, in all branches of engineering, that the application of CFD relies heavily on both verification and validation [231,232]. Verification of CFD simulations covers the quantification of spatial and temporal discretisation errors (see Section 4), whereas general coding errors and bugs are assumed to be solved during code development. Validation by means of comparison to other numerical or analytical solutions, as well as experimental results, should to be a part of every CNWT experiment.

\subsection{Validation Strategies}

From the reviewed literature, four validation strategies can be identified. Comparison of CFD results to:

- Analytical results - For example comparing FSE and velocity data against wave theory results, as in [223]

- PF simulations - CFD results can be shown to converge on PF results as the amplitudes of wave and/or body motions approach zero, shown in [126]

- Other CFD simulations - Comparing CFD against external CFD results has the drawback of not actually checking for physical validity, however can be helpful to evaluate computational efficiency [117]

- Experimental data - This is the most prominent and trusted method, giving a direct comparison against measured physical reality. However, it bears the danger of drawing false conclusions if not taking experimental inaccuracies and scaling issues into account.
Palm et al. [177] identify the influence of physical model inaccuracies on the CNWT model validation, for a novel coupled mooring analysis methodology. For example, the cylindrical buoy used in the physical experiments did not have perfectly sharp bottom corners as in the CNWT model. Also, an offset in the static tension in the mooring lines can be observed between the physical and CNWT models. Prasad et al. [211] detail measurement uncertainties caused by the instrumentation, ranging from $\pm 1 \%$ up to $\pm 2.23 \%$. Similar ranges of measurement uncertainty are found in $[195,197]$.

$\mathrm{Hu}$ et al. [173] and Ransley et al. [212] perform comprehensive validation studies for extreme wave conditions, considering both waveonly and WSI cases. Hu et al. [173] find maximum differences of $15 \%$ in the measured forces compared to experimental results. Study in [143] is the only study to employ the Pearson's coefficient of correlation [266] to quantify the accuracy of the model, rather than well known measures such as mean average error or root mean square error etc. In the study, radiation forces on the WaveBob are measured under different conditions, i.e. ramped-up and steady displacement. Relating experimentally found force data to CFD-based solutions, correlation coefficients between 0.73 and 0.77 are found for the case of ramped-up displacement, whereas almost $100 \%$ correlation is found for the case of steady displacement with coefficients between 0.98 and 0.99 .

Providing high resolution data sets and visualisation, CFD enables the (mostly quantitative) comparison of the flow field with experimental data. As one of the few, authors in $[85,224]$ undertake such a comparison for OWSCs. Employing Particle Image Velocimetry (PIV), Schmitt [85] highlights the complexity and potential inaccuracies of the experimental setup. Hence, comparisons between numerical and physical results in a quantitative manner are hard to conduct. Looking at vortex shedding, Wei et al. [224] find agreement between physical and numerical results. Elhanafi et al. [167] use PIV in order to investigated the 2D flow field around a fixed, offshore OWC. Satisfactory agreement between PIV and CFD are found for both velocity and vorticity.

From validation studies in which quantification of the accuracy is given, it can be generally stated that results with $<10 \%$ difference to the reference data are considered to be effectively validated. However, this number only serves as guideline and the exact desired accuracy must be defined by the user for the specific problem on hand. Furthermore, users are advised to take measurement inaccuracies from experimental setups into account when evaluating the validity of the CFD solution.

\section{CFD software}

To setup a CNWT, numerous toolboxes and software packages are available. Fig. 6 shows the CFD Software used within CNWT WEC analysis and their fraction of the reviewed literature. Ranging from commercial and open source software to in-house developments, these packages can readily be differentiated by availability and accessibility. Commercial tools usually provide easy to use graphical user interfaces (GUIs) and advanced numerical tools, e.g. for body representation.

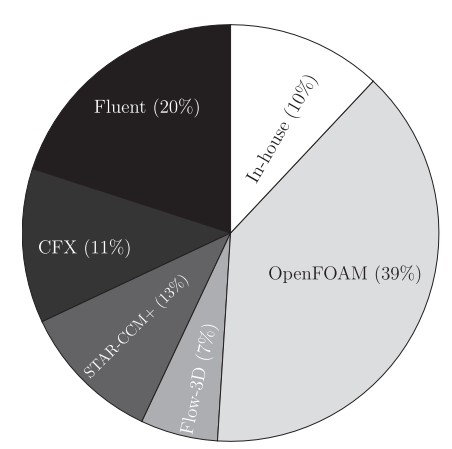

Fig. 6. CFD Software used within CNWT WEC analysis and their shares in the reviewed literature. 
Also, some commercial software suites, e.g. ANSYS, provide multiphysics solvers, allowing fully coupled structural analysis with two-way FSI. However, the considerable license fees and the restricted access to the source code (which makes code tailoring difficult/impossible), possibly hinders the usage of commercial software in WEC applications. The most well used commercial CFD tools include: ANSYS FLUENT and CFX, FLOW-3D and STAR-CCM + .

Avoiding license purchase and enabling source code editing, open source CFD software have gained popularity and are backed by large support communities, forums etc. Drawbacks here are the lack of userfriendly GUIs, often resulting in considerable learning times required to use the software. Furthermore, developments of new (advanced) numerical tools are left to the user or the community, potentially slowing down advancements. One of the most prominent open source representatives is the $\mathrm{C}++$ based Field Operation and Manipulation toolbox OpenFOAM [267]. An overview of the implementation of an OpenFOAM NWT for WEC analysis is given in [127].

Finally, in-house codes are also used to solve the NSE. Either being driven by a specific (physical) problem or the desire to include advanced numerical tools, in-house codes are highly efficient. Their nature, however, makes them unavailable for a large community. Examples of such codes can be found in $[19,32,43,102]$.

Being able to choose between numerous CFD software suites, raises the question of which one to select. As discussed throughout the preceding sections, decision drivers can be identified when looking at the requirements on the CFD software, such as: the available turbulence models, NWMs or BRM. Additional decision drivers may include project time frame, budget and user experience.

Within the reviewed literature, some studies can be identified performing a comparative analysis of different CFD software. Based on the analysis of extreme wave loading, authors in $[37,117]$ consider the FVM solver STAR-CCM + , the CV-FE solver CFX, the in-house Cartesian cut-cell solver AMAZON and a SPH solver. Testing wave-only, fixed structure and dynamic body cases, the authors generally find matching results for the different software. Some errors are found in the heave response for the case of wave-driven motion simulated using the FVM solver. Also, the meshless nature of the SPH solver is stated as being beneficial for extensive body motion. Unfortunately, simulations were not run on a dedicated machine, so that the CPU run times for the different solvers can not be compared.

Studying the hydrodynamic and aerodynamic behaviour of OWCs, study [88] compares the commercial FVM solver FLUENT with an inhouse FEM solver based on two-step semi-implicit Taylor-Galerkin method (Fluinco). Generally good agreement between the codes is found. Investigating the sloshing inside the OWC chamber, more significant differences between the codes are observed. For the specific wave period of $7.5>\mathrm{s}$, a difference in the pneumatic power of $13 \%$ for the two codes is identified. Another code comparison involving OWCs is given in [79], comparing an in-house PF based time-domain solver and the CFD code IH-2VOF. For the free decay test considered, no significant differences between the codes is found. Similarly, FSE data from an irregular sea state, measured inside the OWC chamber are seen to coincide. The authors conclude that the increased efficiency of the inhouse time-domain model surpasses the FVM model by a factor of $\approx 3000$.

More recently, based on the analysis of body dynamics and loads in tsunami waves, study [221] presents a comparison of the opensource CFD toolbox OpenFOAM with ANSYS Fluent. Lower computational cost but also lower accuracy (13\% for OpenFOAM versus $21 \%$ for Fluent) is identified for the particular test case.

\section{Summarising guidelines}

A CNWT comprises the combination of many parts, such as the NWM, BRM, turbulence model, subsystem models, described in Section 3.2 - Section 7. The choice of which method or model to apply for each of the different CNWT parts depends on the WEC type and analysis application, described in Sections 2 and 3, as well as trade-offs between required accuracy and computational efficiency. In some cases, the choice is driven by the methods and models available to the particular CFD software the user has access to. The numerous existing CNWTs reviewed in the paper [15-61,8,62-91,94-157,224,158-196, 198,197,199-223], consisted of a multitude of various combinations of these different parts, depending on their strengths and weaknesses for the given problem at hand. Therefore, in summarising the findings from the review of these CNWTs, this section aims to provide guidelines for the setup and use of CNWTs for WEC experiments.

i) Devices and Application: In the reviewed literature, a trend towards sDOF PA and static OWC systems is observed. This can be explained by the relative simplicity of the WEC structure and required CNWT model, plus the fact that these WEC types present a large portion of real devices thereby delivering relevant case studies. CNWTs are used for a variety of analysis applications, such as investigation of viscous effects, load estimation and performance analysis. Considering OWCs, CNWT setups are seen to reach a level of sophistication in which optimisation and performance studies deliver meaningful results. Whereas, for the remaining device types, the major application is still CNWT model development.

When choosing a modelling tool for WEC analysis, all possible numerical modelling approaches should be evaluated. If the fidelity of CFD is required, and the additional computational burden is justified, the design of the CNWT setup should be specifically tailored for the proposed analysis, to avoid unnecessary complexity and ensure efficient simulations.

ii) Subsystems: A WEC can be broadly be divided into the subsystems: body, PTO, mooring and control system. Different levels of model fidelity for these subsystems can be found in the literature. Depending on the analysis application, using a low fidelity model in any of these subsystems can undermine the accuracy of the end result, and negate the justification of the high computational cost for the improved accuracy of the CFD hydrodynamic model. Therefore, if the inclusion of mooring systems, nonlinear PTOs and control systems is required, the fidelity of the subsystem model has to be chosen based on the analysis requirements.

iii) Discretisation: In vicinity of the free surface interface, structured grids with a spatial discretisation of $\mathcal{O}(10 \mathrm{CPH})$ and $\mathcal{O}(100 \mathrm{CPL})$ can be seen as most widely applied in the community. Similarly $\mathrm{Co}_{\max }$ with values of around 0.5 are commonly used. However, users of CNWTs are advised to perform rigorous (and quantified) convergence studies as proposed in $[200,201]$ for the specific problem on hand, to ensure most accurate and efficient computation.

iv) Turbulence: In the field of naval architecture, great effort has been made in order to formulate best practice guidelines for the inclusion of turbulence. However, due to the fundamental differences between typical systems in that field and WECs, such as large amplitude wave induced resonant motion, these guidelines can hardly be applied on WECs. Based on the problem on hand, CFD engineers are advised to review the necessity of including turbulence closure in the CNWT. If turbulence modelling is required, Table 6 can provide a first indication of the most accurate and efficient turbulence model.

v) Wave generation \& absorption: A variety of approaches for NWMs is seen in the literature, whose accuracy is observed to be dependent on the numerical setup and the considered sea state. Hence, the choice of a NWM for a given problem must be driven by a rigorous, quantitative assessment as proposed in [223].

vi) Body representation method: The boundary fitted mesh coupled with mesh distortion is the most widely used BRM, but has considerable limitations in the allowable displacement amplitude. Numerical efficiency and its readily available implementation in the commonly used CFD software, render this method a good 
starting point for numerical model setup. However, if large amplitude displacements or multi-DOF body motion must be captured, more advanced methods such as overset grids may be considered.

vii) Validation: In the reviewed literature, a considerable number of studies only provide qualitative descriptions of the achieved accuracy in a semantic way. Missing quantification undermines confidence in statements such as good or very good agreement with validation data. Therefore, quantification of the validation should always be provided. Furthermore, if validated against physical wave tank test data, the uncertainty of the experimental setup must be considered. For example, the typical accuracy of resistance wave gauges is $\pm 0.5 \mathrm{~mm}$ [268], and since most experimental test are performed at $1 / 10-1 / 40$ scales, the experimental uncertainty is in the order of $\mathcal{O}(10 \%)$. Thus, if deviations to experimental reference data of order $<10 \%$ are found, the numerical model can effectively be considered as validated.

\section{Conclusions}

This review reveals the effort of the numerical modelling community in the field of ocean wave energy to enhance the capabilities of CNWTs for WEC experiments. Starting with the pioneering work by authors in [15] and [16], increasing model fidelity and capabilities can be observed. However, the reviewed literature also reveals model shortcomings and inconsistent fidelity for different WEC subsystems, which impede the development of a holistic high fidelity CNWT WEC model. To tackle this challenge and progress towards such a model, different work packages can be identified from the literature.

- Wave Generation \& Absorption: A variety of NWMs are available for wave generation and absorption within a CNWT. However, due to a lack of comprehensive comparison, the choice of NWM for a given problem is mostly driven by the availability within the employed CFD software. Hence, it is desirable to formulate guidelines for NWM selection based on quantitative comparisons of different NWMs in terms of accuracy and computational efficiency. A first step towards such guidelines has been taken by authors in [251,223].

- Multi-DOF \& Multi-body WECs: Regarding dynamical systems, the literature reveals a focus on sDOF devices. In the physical world, these systems can rarely be found. Hence, the ability to model mDOF systems within a CNWT framework is required. Similarly, the literature shows a trend towards single body devices. Although these may be more prominent in physical applications, limiting CNWT experiments to single bodies would exclude a considerable number of WEC devices. Using advanced BRM, some studies present possibilities to enable multi-body CNWT experiments [21,102,187], however, availability of advanced BRMs is tied to the employed CFD software. Based on the fact that the open source toolbox OpenFOAM is widely employed in the field of ocean wave energy, developing new BRMs for OpenFOAM would provide advanced methods to a wide community.

- Realistic PTO Representation: To conduct comprehensive analysis on WEC performance, loading or control strategies, high fidelity model representation of WEC subsystems is required to justify the computational cost for the high fidelity CFD hydrodynamic simulation. Shortcomings can be identified for the PTO systems. Mostly modelled as linear spring-damper systems, these simplistic models do not represent realistic PTO dynamics and inefficiencies, thereby undermining the overall fidelity to the WEC model. Therefore effort should be made to incorporate more realistic, nonlinear PTO models.

- Control Strategy: Similar to the requirement of realistic PTO models, the incorporation of advanced control strategies into the WEC model is desirable. The nonlinear hydrodynamic environment of the CNWT allows for more realistic evaluation of control strategies, thereby accelerating the development and implementation of energy maximising control for WECs.

\section{Acknowledgment}

This paper is based upon work supported by Science Foundation Ireland under Grant No. 13/IA/1886.

\section{References}

[1] de O. Falcão AF. Wave energy utilization: A review of the technologies. Renew Sustain Energy Rev 2010;14:899-918.

[2] Weber J. Wec technology readiness and performance matrix - finding the best research technology development trajectory. In: Proceedings of the 4th International Conference on Ocean Energy, 2012.

[3] Tanizawa, Katsuji, Naito S. A study on parametric roll motions by fully nonlinear numerical wave tank. In: Proceedings of the 7th International Offshore and Polar Engineering Conference, 1997.

[4] Guanche R. On the importance of calibration and validation procedures: hybrid modeling. In: Proceedings of the BCAM Workshop Hydrodynamics of Wave Energy Converters 2017, 2017.

[5] Faltinsen OM. Sea Loads on Ships and Offshore Structures 1. Cambridge University Press; 1993. (URL 1).

[6] Ferziger JH, Peric M. Computational Methods for Fluid Dynamics. Springer-Verlag $\mathrm{GmbH} ; 2001$.

[7] Versteeg H, Malalasekra W. An Introduction to Computational Fluid Dynamics. Prentice Hall; 2007.

[8] Li Y, Yu Y-H. A synthesis of numerical methods for modeling wave energy converter-point absrobers. Renew Sustain Energy Rev 2012;16:4352-64.

[9] Folley M, Babarit A, Child B, Forehand D, O'Boyle L, Silverthorne K, Spinneken J, Stratigaki V, Troch P. A Review of Numerical Modelling of Wave Energy Converter Arrays. In: Proceedings of the ASME 31st International Conference on Ocean, Offshore and Arctic Engineering, 2012.

[10] Coe RG, Neary VS. Review of Methods for Modelling Wave Energy Converter Survival in Extreme Sea States. In: Proceedings of the 2nd Marine Energy Technology Symposium, 2014.

[11] Bouhrim H, El Marjani A. On numerical modeling in owc systems for wave energy conversion. In: Proceedings of the 2014 Internation Renewable and Sustainable Energy Conference (IRSEC), 2014.

[12] Day AH, Babarit A, Fontaine A, He Y-P, Karaskowski M, Murai M, et al. Hydrodynamic modelling of marine renewable energy devices: A state of the art review. Ocean Eng 2015;108:46-69.

[13] Wolgamot HA, Fitzgerald CJ. Nonlinear hydrodynamic and real fluid effects on wave energy converters. Proc Inst Mech Eng, Part A: J Power Energy 2015;229:772-94.

[14] Penalba M, Giorgi G, Ringwood JV. Mathematical modelling of wave energy converters: A review of nonlinear approaches. Renew Sustain Energy Rev 2017;78:1188-207.

[15] Qian L, Mingham C, Causon D, Ingram D. Numerical simulation of a wave driven rotating vane using a two-fluid solver. In: Proceedings of the IASTED International Conference on Environmental Modelling and Simulation, 2004.

[16] Clauss GF, Schmittner CE, Stueck R. Numerical wave tank - simulation of extreme waves for the investigation of structural responses. In: Proceedings of the ASME 24th International Conference on Offshore Mechanics and Arctic Engineering, 2005.

[17] Qian L, Mingham C, Causon D, Ingram D, Folley M, Whittaker T. Numerical simulation of wave power devices using a two-fluid free surface solver. Mod Phys Lett B 2005;19:1479-82.

[18] Alves M, Sarmento A. Non-Linear and Viscous Analisys of the DIffraction Flow in Owc Wave Power Plants. In: Proceedings of the 16th International Offshore and Polar Engineering Conference, 2006.

[19] Greaves D. Viscous waves and wave-structure interaction in a tank using adapting quadtree grids. J Fluids Struct 2007;23(8):1149-67.

[20] Liu Z, Hyun B-S, Jin J, Numerical wave tanke using two-phase VOFmodel, In: Proceedings of the KOSMEE Fall Annual Meetring, 2007.

[21] Agamloh EB, Wallace AK, von Jouanne A. Application of fluid-structure interaction simulation of an ocean wave energy extraction device. Renew Energy 2008;33:748-57.

[22] Liu Z, Hyun B-S, Hong K-Y. Application of numerical wave tank to owc air chamber for wave energy conversion. In: Proceedings of the 18th International Offshore and Polar Engineering Conference, 2008.

[23] Liu Z, Hyun B-S, Jin J. Numerical prediction for overtopping perfor1435mance of OWEC, in: OCEANS 2008 - MTS/IEEE Kobe Techno-Ocean,IEEE, 2008.

[24] Liu Z, Hyun B-S, Jin J-Y. Numerical analysis of wave field in OWC chamber using VOF model. J Ocean Eng Technol 2008;22:1-6.

[25] Nam BW, Shin SH, Hong KY, Hong SW. Numerical simulation of wave flow over the spiral reef overtopping device. In: Proceedings of the 8th ISOPE Pacific/Asia Offshore Mechanics Symposium, 2008.

[26] Victor L, Troch P, Vanneste D. Experimental and numerical study of the hydrodynamic behavior of wave energy converters based on wave overtopping. In: Proceedings of the 2nd International Conference on Ocean Energy, 2008.

[27] Bhinder MA, Mingham CG, Causon DM, Rahmati MT, Aggidis GA, Chaplin RV. A Joint Numerical and Experimental Study of a Surging Point Absorbing Wave 
Energy Converter (WRASPA). In: Proceedings of the AMSE 28th International Conference on Ocean, Offshore and Arctic Engineering, 2009.

[28] Bhinder MA, Mingham CG, Causon DM, Rahmati MT, Aggidis GA, Chaplin R. Numerical and Experimental Study of a Surging Point Absorber Wave Energy Converter. In: Proceedings of the 8th European Wave and Tidal Energy Conference, 2009.

[29] Bhinder M, Mingham C, Causon D, Rahmati M, Aggidis G, Chaplin R. Numerical and experimental study of a point absorbing wave energy converter in regular waves. In: 2009 International Conference on Clean Electrical Power, 2009.

[30] Babarit A, Mouslim H, Clement A, Laporte-Weywada P. On the numerical modelling of the non linear behaviour of a wave energy converter. In: Proceedings of the ASME 28th International Conference on Ocean, Offshore and Arctic Engineering, 2009.

[31] Gomes M, Isoldi L, Olinto C, Rocha L, Souza J. Computational modeling of a regular wave tank. In: Proceedings of the Third Southern Conference on Computational Modelling, 2009, pp. 60 - 65.

[32] Hu Z, Causon D, Mingham C, Qian L. Numerical wave tank study of a wave energy converter in heave. In: Proceedings of the 19th International Offshore and Polar Engineering Conference, 2009

[33] Liu Z, Shi H, Hyun B-S. Practical design and investigation of the breakwater owc facility in china. In: Proceedings of the 8th European Wave and Tidal Energy Conference, 2009.

[34] Liu Z, Hyun B-S, Hong K-Y, Lee Y-Y. Investigation on integrated system of chamber and turbine for owc wave energy convertor, In: Proceedings of the 19th International Offshore and Polar Engineering Conference, 2009.

[35] Thilleul O, Baudry V, Guilcher P, Scolan Y-M, Jacquin E, Babarit A, Locuratolo P, Larivain A. Complementray yse of linear potential code, a rans and a sph solver for the optimisation of a wave energy converter. In: Proceedings of the 8th European Wave and Tidal Energy Conference, 2009.

[36] Victor L, Troch P, Kofoed J. Prediction of the individual wave overtopping volumes of a wave energy converter using experimental testing and first numerical model results. In: Proceedings of the 8th European Wave and Tidal Energy Conference, 2009.

[37] Westphalen J, Greaves D, Williams C, Taylor P, Causon D, Mingham C, Hu Z Stansby P, Rogers B, Omidvar P. Extreme Wave Loading on Offshore Wave Energy Devices using CFD: a Hierarchical Team Approach. In: Proceedings of the 8th European Wave and Tidal Energy Conference, 2009.

[38] Davyt D, Ramalhais R, Didier, E. Numerical analysis of regular wavesover an onshore oscillating water column, In: Proceedings of the 13thBrazilian Congress of Thermal Sciences and Engineering, 2010.

[39] Hu Z, Causon D, Mngham C, Qian L. Numerical simulation of nonlinear wave interactions with a wave energy converter. In: Proceedings of the 20th International Offshore and Polar Engineering Conference, 2010.

[40] Li Y, Lin M. Wave-body interactions for a surface-piercing body in water of finite depth. J Hydrodyn, Ser B 2010;22:745-52.

[41] Liu Z, Hyun B-S, Shi H, Hong K. Practical simulation of oscillating water column chamber for wave energy conversion. Int J Green Energy 2010;7:337-46.

[42] Prasad D, Zullah MA, Ahmed MR, Lee Y-H. Effect of front guide nozzle shape on the flow characteristics in an augmentation channel of a direct drive turbine for wave power generation. Sci China Ser E: Technol Sci 2010;53:46-51.

[43] Sanders J, Dolbow JE, Mucha PJ, Laursen TA. A new method for simulating rigid body motion in incompressible two-phase flow. Int J Numer Methods Fluids 2010;67(6):713-32

[44] Westphalen J, Greaves D, Hunt-Raby A, Williams C, Stansby P, Stallard T. Numerical simulation of a floating body in multible degrees of freedom. Proc Mar Renew Offshore Wind Energy 2010.

[45] Zhang Y, Zou Q, Greaves D, Reeve D, Raby A, Graham D, James P. An investigation of the hydrodynamic characteristics of an oscillating water column device using a level set immersed boundary model. In: Proceedings of the 20th International Offshore and Polar Engineering Conference, 2010.

[46] Zullah MA, Prasad D, Ahmed MR, Lee Y-H. Performance analysis of a wave energy converter using numerical simulation technique. Sci China Ser E: Technol Sci 2010;53:13-8.

[47] Bhinder MA, Babarit A, Gentaz L, Ferrant P. Assessment of Viscous Damping via 3D-CFD Modeling of a Floating Wave Energy Device. In: Proceedings of the 9th European Wave and Tidal Energy Conference, 2011.

[48] Conde J, Teixeira P, Didier E. Numerical simulation of an oscillating water column wave energy converter: Comparison of two numerical codes. In: Proceedings of the 21st International Offshore and Polar Engineering Conference, 2011.

[49] Hu ZZ, Causon DM, Mingham CG, Qian L. Numerical simulation of floating bodies in extreme free surface waves. Nat Hazards Earth Syst Sci 2011;11:519-27.

[50] Sentürk U, Özdamar A. Modelling the interaction between water waves and the oscillating water column wave energy device. Math Comput Appl 2011;16:630-40.

[51] Liu Z, Hyun B-S, Hong K. Numerical study of air chamber for oscillating water column wave energy convertor. China Ocean Eng 2011;25(1):169-78.

[52] Westphalen J. Extreme wave loading on offshore wave energy devices using CFD, (Ph.D. Thesis). Univeristy of Plymouth; 2011.

[53] Winchester J, McCabe A, Aggidis G. CFD analysis of a multi-axis wave energy converter with novel geometry. In: Proceedings of the 9th European Wave and Tidal Energy Conference, 2011.

[54] Yu Y, Li Y. A RANS simulation of the heave response of a two-body floating point absorber. In: Proceedings of the 21st International Offshore and Polar Engineering Conference, 2011.

[55] Yu Y, Li Y. Preliminary results of a RANS simulation for a floating point absorber wave energy system under extreme wave conditions. In: Proceedings of the 30th International Conference on Ocean, Offshore, and Arctic Engineering, 2011.
[56] Bhinder M, Babarit A, Gentaz L, Ferrant P. Effect of viscous forces on the performance of a surging wave energy converter. In: Proceedings of the 22nd International Conference on Ocean, Offshore and Arctic Engineering, 2012

[57] Cho YJ, Zullah MA, Faizal M, Choi YD, Lee YH. A study on the flow characteristics of a direct drive turbine for energy conversion generation by experiment and CFD, IOP Conference Series: Earth and Environmental Science (2012) 15042040

[58] Finnegan W, Goggins J. Numerical simulation of linear water waves and wave-structure interaction. Ocean Eng 2012;43:23-31.

[59] Grimmler J, Lopes N, Souza J, dos Santos E, Isoldi L, Gomes M, Rocha L. Numerical study about the shape influence of the hydropneumatic chamber in an owc wave energy converter. In: Proceedings of the 14th Brazilian Congress of Thermal Sciences and Engineering, 2012.

[60] Jin J, Liu Z, Hong K-Y, Hyun B-S. 3d numerical investigation on reservoir system for an overtopping wave energy convertor. J Navig Port Res 2012;36:97-103.

[61] Jin J, Liu Z, Hyun B-S, Hong K. Effects of wave direction on performance of oscillating water column type wave energy convertor. In: Proceedings of the 22nd International Offshore and Polar Engineering Conference, 2012.

[62] Li L, Tan M, Blake J. OpenFOAM simulation of regular wave and wave load on cylinder. In: Proceedings of the 15th Numerical Towing Tank Symposium, 2012, pp. $146-151$.

[63] Liu Z, Jin J-Y, Hyun B-S, Hong K. Review of Application of VOF-Based NWT on Integrated OWC System. J Korean Soc Mar Environ Eng 2012;15:111-7.

[64] Lopez I, Iglesias G, Lopez M, Castro F, Rodríguez MÁ. Turbine-chamber coupling in an owc wave energy converter, Coastal Engineering Proceedings 1.

[65] Mirzaii I, Passandideh-Fard M. Modeling free surface flows in presence of an arbitrary moving object. Int J Multiph Flow 2012;39:216-26.

[66] Puolakka O, Mikkola T. Radiation moment on vertical bottom-hinged flap. In: Proceedings of the 15th Numerical Towing Tank Symposium, 2012, pp. $146-151$.

[67] Prasad D, Ahmed MR, Lee Y-H. Performance studies on a direct drive turbine for wave power generation in a numerical wave tank. In: Proceedings of the 1st Asian Wave and Tidal Energy Conference, 2012.

[68] Schmitt P, Bourdier S, Sarkar D, Renzi E, Dias F, Doherty K, Whittaker T, van 't Hoff J. Hydrodynamic loading on a bottom hinged oscillating wave surge converter. In: Proceedings of the 22rd International Offshore and Polar Engineering Conference, 2012.

[69] Schmitt P, Doherty K, Clabby D, Whittaker T. The opportunities and limitations of usinf CFD in the development of wave energy converters. In: Proceedings of the International Conference on Marine \& Offshore Renewable Energy, 2012.

[70] Souza JA, Isoldi LA, dos Santos ED, das Neves Gomes M, Rocha LAO. Numerical simulation of sea wave energy converters using the OpenFOAM software. Proc 14th Braz Congr Therm Sci Eng 2012.

[71] Thaker JP, Banerjee J. Numerical simulation of periodic motion of two phases in a two-dimensional channel: Application to wave energy converter. In: Proceedings of the 39th National Conference on Fluid Mechanics and Fluid Power, 2012.

[72] Westphalen J, Greaves D, Williams C, Hunt-Raby A, Zang J. Focused waves and wave-structure interaction in a numerical wave tank. Ocean Eng 2012;45:9-21.

[73] Zhang Y, Zou Q, Greaves D. Air-water two-phase flow modelling of hydrodynamic performance of an oscillating water column device. Renew Energy 2012;41:159-70.

[74] Akimoto H, Tanaka K. Conceptual study of a drag type water turbine for electricity generation from wave power. In: Proceedings of the 12th International Symposium on Fluid Control, Measurement and Visualization, 2013.

[75] Anbarsooz M, Passandideh-Fard M, Moghiman M. Fully nonlinear viscous wave generation in numerical wave tanks. Ocean Eng 2013;59:73-85.

[76] Bouali B, Larbi S. Contribution to the geometry optimization of an oscillating water column wave energy converter. Energy Procedia 2013;36:565-73.

[77] Caskey C, Jeans T. Analysis of a cycloidal wave energy converter using unsteady reynolds averaged navier-stokes simulation. In: Proceedings of the 10th European Wave and Tidal Energy Conference, 2013.

[78] Davidson J, Giorgi S, Ringwood J. Linear parametric hydrodynamic models based on numerical wave tank experiments. In: Proceedings of the 10th European Wave and Tidal Energy Conference, 2013.

[79] Iturrioz A, Guanche R, Armesto J, Vidal C, Losada I. Experimental and numerical development of a floating multi-chamber OWC device. In: Proceedings of the 10th European Wave and Tidal Energy Conference, 2013.

[80] Li K-M, Parthasarathy N, Choi Y, Lee Y. Study on wave energy generation of floating bodies for energy absoprtion by CFD. In: Proceedings of the 23rd International Offshore and Polar Engineering Conference, 2013.

[81] Nicholls-Lee R, Walker A, Hindley S, Argall R. Coupled multi-phase cfd and transient mooring analysis of the floating wave energy converter owel. In: ASME 2013 Proceedings of the 32nd International Conference on Ocean, Offshore and Arctic Engineering, 2013.

[82] Palm J, Eskilsson C, Paredes G, Bergdahl L. CFD Simulation of a Moored Floating Wave Energy Converter. In: Proceedings of the 10th European Wave and Tidal Energy Conference, 2013.

[83] Ransley E, Hann M, Greaves D, Raby A, Simmonds D. Numerical and physical modeling of extreme waves at wave hub. J Coast Res 2013;165:1645-50.

[84] Ransley E, Hann M, Greaves D, Raby A, Simmonds D. Numerical and Physical Modelling of Extreme Wave Impacts on a Fixed Truncated Circular Cylinder. In: Proceedings of the 10th European wave and tidal energy conference, 2013.

[85] Schmitt P. Investigation of the near flow field of bottom hinged flap type wave energy converters, Ph.D. Thesis. School of Planning, Architecture and Civil Engineering, Queen's Univeristy Belfast; 2013.

[86] Schmitt P, Doherty K, Whittaker T. Shape optimisation of a bottom hinged flap type wave energy converter. In: Proceedings of the Conference on Maritime Energy, 2013. 
[87] Souza JA, dos Santos ED, Isoldi LA. Numerical simulation of an owc1655 device, In: Proceedings of the 22nd International Congress of MechanicalEngineering, 2013.

[88] Teixeira PR, Davyt DP, Didier E, Ramalhais R. Numerical simulation of an oscillating water column device using a code based on navier-stokes equations. Energy 2013;61:513-30.

[89] Vyzikas T, Ransley E, Hann M, Magagna D, Greaves D, Simmonds D, Magar V, Conley D. Integrated numerical modelling system for extreme wave events at the wave hub site. In: Proceedings of ICE conference on coasts, marine structures and breakwaters, 2013.

[90] Wei Y, Rafiee A, Dias F. On the viscous effects in the interaction of water waves with an oscillating wave surge converter. In: Proceedings of the 10th European Wave and Tidal Energy Conference, 2013.

[91] Wei Y, Rafiee A, Elsaesser B, Dias F. Numerical simulation of an oscillating wave surge converter. In: Proceedings of the ASME 2013 32nd International Conference on Ocean, Offshore and Arctic Engineering, 2013.

[92] Yu Y-H, Li Y. Reynolds-averaged navier-stokes simulation of the heave performance of a two-body floating-point absorber wave energy system. Comput Fluids 2013;73:104-14.

[93] Zullah MA, Lee Y. Performance evaluation of a direct drive wave energy converter using CFD. Renew Energy 2013;49:237-41.

[94] Akimoto H, Kim YY, Tanaka K. Performance prediction of the rotational wave energy converter using single-bucket drag type turbine. In: Proceedings of the ASME 33rd International Conference on Ocean, Offshore and Arctic Engineering, 2014

[95] Anbarsooz M, Passandideh-Fard M, Moghiman M. Numerical simulation of a submerged cylindrical wave energy converter. Renew Energy 2014;64:132-43.

[96] Armesto JA, Guanche R, Iturrioz A, Vidal C, Losada IJ. Identification of state-space coefficients for oscillating water columns using temporal series. Ocean Eng 2014:79:43-9.

[97] Asmuth H, Schmitt P, Elsaesser B, Henry H. Determination of non-linear damping coefficients of botom-hinged oscillating wave surge converters using numerical free decay tests. In: Proceedings of the 1st International Conference on Renewable Energies Offshore, 2014.

[98] Bøckmann A, Pâkozdi C, Kristiansen T, Jang H, Kim J. An experimental and computational development of a benchmark solution for the validation of numerical wave tanks. In: Volume 2: CFD and VIV, ASME International, 2014.

[99] Chen L, Zang J, Hillis A, Morgan G, Plummer A. Numerical investigation of wavestructure interaction using OpenFOAM. Ocean Eng 2014;88:91-109.

[100] Chen L, Sun L, Zang J, Hillis A. Numerical Simulation of Wave-Induced Roll of a 2D Rectangular Barge Using OpenFOAM. In: Proceedings of the 29th International Workshop on Water Waves and Floating Bodies, 2014.

[101] Davidson J, Giorgi S, Ringwood J. Numerical wave tank identification of nonlinear discrete time hydrodynamic models. In: Proceedings of the 1st International Conference on Renewable Energies Offshore, 2014.

[102] Ghasemi A, Pathak A, Raessi M. Computational simulation of the interactions between moving rigid bodies and incompressible two-fluid flows. Comput Fluids 2014;94:1-13.

[103] Henry A, Rafiee A, Schmitt P, Dias F, Whittaker T. The characteristics of wave impacts on a oscillating wave surge converter. J Ocean Wind Energy 2014;1:101-10.

[104] Iturrioz A, Guanche R, Armesto J, Alves M, Vidal C, Losada I. Time-domain modeling of a fixed detached oscillating water column towards a floating multi chamber device. Ocean Eng 2014;76:65-74.

[105] King A. Numerical modelling of the 'bombora' wave energy conversion device. In: Proceedings of the 19th Australasian Fluid Mechanics Conference, 2014.

[106] López I, Pereiras B, Castro F, Iglesias G. Optimisation of turbine-induced damping for an OWC wave energy converter using a RANS-VOF numerical model. Appl Energy 2014;127:105-14.

[107] Luo Y, Nader J-R, Cooper P, Zhu S-P. Nonlinear 2D analysis of the efficiency of fixed oscillating water column wave energy converters. Renew Energy 2014;64:255-65.

[108] Luo Y, Wang Z, Peng G, Xiao Y, Zhai L, Liu X, et al. Numerical simulation of a heave-only floating OWC (oscillating water column) device. Energy 2014;76:799-806.

[109] Prasad DD, Ahmed MR, Lee Y-H. Flow and performance characteristics of a direct drive turbine for wave power generation. Ocean Eng 2014;81:39-49.

[110] Simonetti I, Cappietti L, El Safi H, Oumeraci H. 3D Numerical modelling of oscillating water column wave energy conversion devices: current knowledge and OpenFOAM implementation. In: Proceedings of the 1st International Conference on Renewable Energies Offshore, 2014.

[111] Stratigak V. Experimental study and numverical modelling of intra-array interactions and extra-array effects of wave energy convertera arrays (Ph.D. thesis). Faculteit Ingenieurswetenschappen en Architectuur,Universiteit Gent; 2014

[112] Seibt F, Letzow M, Gomes M, Souza J, Rocha L, dos Santos E, et al. Computational modeling applied to the study of wave energy converters (WEC). Mar Syst Ocean Technol 2014;9:77-84.

[113] Seibt FM, Couto EC, dos Santos ED, Isoldi LA, Rocha LAO, de Freitas Teixeira PR. Numerical study on the effect of submerged depth on the horizontal plate wave energy converter. China Ocean Eng 2014;28:687-700.

[114] Seibt FM, Couto EC, de F. Teixeira PR, dos Santos ED, Rocha LAO, Isoldi LA. Numerical analysis of the fluid-dynamic behavior of a submerged plate wave energy converter. Comput Therm Sci: Int J 2014;6:525-34.

[115] dos Santos ED, Machado BN, Zanella MM, das Neves Gomes M, Souza JA, Isoldi LA, et al. Numerical study of the effect of the relative depth on the overtopping wave energy converters according to constructal design. Defect Diffus Forum
2014;348:232-44

[116] Wei Y, Henry A, Kimmoun O, Dias F. Numerical study of wave slamming on an oscillating flap. In: Proceedings of the ASME 33rd International Conference on Ocean, Offshore and Arctic Engineering, 2014.

[117] Westphalen J, Greaves DM, Hu AR, Causon DM, Mingham CG, Omidvar P, Stansby $\mathrm{PK}$, Rogers BD. Investigation of wave-structure interaction using state of the art CFD techniques. Open J Fluid Dyn 2014;4:18-43.

[118] Zaoui L, Bouali B, Larbi S, Benchatti A. Performance analysis of a 3D axisymmetric oscillating water column. Energy Procedia 2014;50:246-54.

[119] Akimoto H, Tanaka K, Kim Y. Drag-type cross-flow water turbine for capturing energy from the orbital fluid motion in ocean wave. Renew Energy 2015;76:196-203.

[120] Bhinder MA, Babarit A, Gentaz L, Ferrant P. Potential time domain model with viscous correction and CFD analysis of a generic surging flaoting wave energy converter. Int J Mar Energy 2015;10:70-96.

[121] Buccino M, Dentale F, Salerno D, Vicinanza D. CFD numerical simulation and experiments on seawave slot-cone generator in random wave. In: Proceedings of the 11th European Wave and Tidal Energy Conference, 2015.

[122] Chen L. Modelling of marine renewable energy, Ph.D. thesis, Univeristy of Bath. Department of Architecture and Civil Engineering; 2015.

[123] Chen L, Zang J, Hillis AJ, Plummer AR. Hydrodynamics performance of a flap-type wave energy converter in viscous flow. In: Proceedings of the 25th International Ocean and Polar Engineering Conference, 2015.

[124] Chenari B, Saadatian SS, Ferreira AD. Numerical modelling of regular waves propagation and breaking using waves2foam. J Clean Energy Technol 2015;3:276-81.

[125] Chen Z, Singh PM, Choi Y-D. Structural analysis on the arm and floater structure of a wave energy converter. KSFM J Fluid Mach 2015;18:5-11.

[126] Davidson J, Giorgi S, Ringwood JV. Linear parametric hydrodynamic models for ocean wave energy converters identified from numerical wave tank experiments. Ocean Eng 2015;103:31-9.

[127] Davidson J, Cathelain M, Guillemet L, Le Huec T, Ringwood J. Implementation of an openfoam numerical wave tank for wave energy experiments. In: Proceedings of the 11th European Wave and Tidal Energy Conference, 2015.

[128] Devolder B, Schmitt P, Rauwoens O, Elsaesser B, Troch P. A review of the implicit motion solver algorithm in OpenFOAM to simulate a heaving buoy. In: Proceedings of the 18th Numerical Towing Tank Symposium, 2015.

[129] Ding L, Zhang L, Wu C, Mao X, Jiang D. Flow induced motion and energy harvesting of bluff bodies with different cross sections. Energy Convers Manag 2015;91:416-26.

[130] Dimakopoulos A, Cooker M, Lopez E, Longo D, Pinguet R. Flow characterisation and numerical modelling of owc wave energy converters. In: Proceedings of the 11th European Wave and Tidal Energy Conference, 2015.

[131] Eskilsson C, Palm J, Kofoed J, Friis-Madsen E. CFD study of the overtopping discharge of the Wave dragon wave energy converter. In: Proceedings of the 1 st International Conference on Renewable Energies Offshore, CRC Press, 2014.

[132] Eskilsson C, Palm J, Engsig-Karup AP, Bosi U, Ricchiuto M. Wave induced motions of point-absorbers: a hierarchical investigation of hydrodynamic models. In: Proceedings of the 11th European Wave and Tidal Energy Conference, 2015.

[133] Fresco LD, Traverso A, Barberis S, Guglielmino E, Garrone M. Off-shore wave energy harvesting: A WEC-microturbine system: Harvesting and storing energy for off-shore applications. Oceans 2015.

[134] Finnegan W, Goggins J. Linear irregular wave generation in a numerical wave tank. Appl Ocean Res 2015;52:188-200.

[135] Giorgi S, Davidson J, Ringwood J. Identification of nonlinear excitation force kernels using numerical wave tank experiments. In: Proceedings of the 11th European Wave and Tidal Energy Conference, 2015.

[136] Gomes M, dos Santos E, Isoldi L, Rocha L. Numerical analysis including pressure drop in oscillating water column device. Open Eng 2015;5:229-37.

[137] Heilskov NF. Structural design of wave energy converters - State-of-the-Art and implementation of design tools for floating wave energy converters, Tech. rep., Danish Hydraulic Institute DHI (2015).

[138] Iturrioz A, Guanche R, Lara J, Vidal C, Losada I. Validation of OpenFOAM for oscillating water column three-dimensional modeling. Ocean Eng 2015;107:222-36.

[139] Kim B-H, Wata J, Zullah MA, Ahmed MR, Lee Y-H. Numerical and experimental studies on the PTO system of a novel floating wave energy converter. Renew Energy 2015;79:111-21.

[140] Kamath A, Bihs H, Arntsen ØA. Numerical investigations of the hydrodynamics of an oscillating water column device. Ocean Eng 2015;102:40-50.

[141] Kamath A, Bihs H, Arntsen ØA. Numerical modeling of power take-off damping in an oscillating water column device. Int J Mar Energy 2015;10:1-16.

[142] Li L, Tan M, Blake J. Numerical simulation of multi-body wave energy converter. In: Proceedings of the 25th International Ocean and Polar Engineering Conference, 2015.

[143] Mishra V, Beatty S, Buckham B, Oshkai P, Crawford C. Application of an arbitrary mesh interface fo CFD simulation of an oscillating wave energy converter. In Proceedings of the 11th European Wave and Tidal Energy Conference, 2015.

[144] Medina-Lopez E, Allsop W, Dimakopoulos D, Bruce T. Conjectures on the failure of the owc breakwater at Mutriku. In: Proceedings of Coastal Structures, 2015.

[145] Mendoza E, Chávez X, Alcérreca-Huerta JC, Silva R. Hydrodynamic behavior of a new wave energy convertor: the blow-jet. Ocean Eng 2015;106:252-60.

[146] Nematbakhsh A, Michailides C, Gao Z, Moan T. Comparison of experimental data of a moored multibody wave energy device with a hybrid cfd and biem numerical analysis framework. In: Proceedings of the ASME 34th International Conference on Ocean, Offshore and Arctic Engineering, 2015. 
[147] Palm J, Eskilsson C, Bergdahl L, Paredes G. CFD study of a moored floating cylinder: Comparison with experimental data. In: Proceedings of the 1st International Conference on Renewable Energies Offshore, 2014.

[148] Reis M, Didier E, Dias J, Mendonca A, Conde J, Neves M, Fortes C, Teixeira P. Development of an integrated tool for numerical modelling ofowc-wecs in vertical breakwaters, In: Proceedings of the 2nd International1860 Workshop on Hydraulic Structures, 2015.

[149] Ringwood J, Davidson J, Giorgi S. Optimising numerical wave tank tests for the parametric identification of wave energy device models. In: Proceedings of the ASME 34th International Conference on Ocean, Offshore and Arctic Engineering, 2015.

[150] Ransley EJ. Survivability of wave energy converter and mooring coupledsysyem using $\mathrm{cfd}$ (Ph.D. thesis). School of Marine Science and Engineeting,Univeristy of Plymouth; 2015.

[151] Rafiee A, Fievez J. Numerical Prediction of Extreme Loads on the CETO Wave Energy Converter. In: Proceedings of the 11th European Wave and Tidal Energy Conference, 2015.

[152] Schmitt P, Elsaesser B. On the use of OpenFOAM to model oscillating wave surge converters. Ocean Eng 2015;108:98-104.

[153] Simonetti I, Cappietti L, El Safti H, Manfrida G, Matthies H, Oumeraci H. The use of OpenFOAM as a virtual laboratory to simulate oscillating water column wave energy converters. In: Proceedings of the VI International Conference on Computational Methods in Marine Engineering, 2015.

[154] Stansby P, Gu H, Moreno EC, Stallard T. Drag minimisation for high capture width with three float wave energy converter M4. In: Proceedings of the 11th European Wave and Tidal Energy Conference, 2015.

[155] Scarpetta F, Martina G, Torresi M, Camporeale SM. Cfd analysis of the wave interaction with both a submerged impermeable breakwater and one embedding an owc device. In: Proceedings of the 11th European Wave and Tidal Energy Conference, 2015.

[156] Thilleul O, Menard R, Surmont F, Berhault C, Poirier JC, Cany F, ASD, Bossard J. Evaluation of response bases design method and validation of wave loads computations in CFD. In: Proceedings of the 11th European Wave and Tidal Energy Conference, 2015.

[157] Verduzco-Zapata MG, Ocampo-Torres FJ. Study of a 6 DOF wave energy converter interacting with regular waves using 3D CFD. In: Proceedings of the 11th European Wave and Tidal Energy Conference, 2015.

[158] Wei Y, Dias F. Numerical study of three dimensional effects of wave impact on an oscillating wave surge converter. In: Proceedings of the ASME 34th International Conference on Ocean, Offshore and Arctic Engineering, 2015.

[159] Anbarsooz M, Faramarzi A, Ghasemi A. A numerical study on the performance of fixed oscillating water column wave energy converter at steep waves. In: Proceedings of the ASME 2016 Power Conference, 2016.

[160] Bharath A, Penesis I, Nader J-R, Macfarlane G. Non-Linear CFD Modelling of a Submerged Sphere Wave Energy Converter. In: Proceedings of the 3rd Asian Wave and Tidal Energy Conference, 2016.

[161] Chen L, Sun L, Zang J, Hillis A, Plummer A. Numerical study of roll motion of a 2D floating structure in viscous flow. J Hydrodyn, Ser B 2016;28:544-63.

[162] Chen W, Zhang Y, Yu H. Numerical study on the performance of a twin-raft wave energy dissipator in a stilling basin. J Fluids Struct 2016;66:170-82.

[163] Coiro DP, Troise G, Calise G, Bizzarrini N. Wave energy conversion through a point pivoted absorber: numerical and experimental tests on a scaled model. Renew Energy 2016;87:317-25.

[164] Davidson J, Giorgi S, Ringwood JV. Identification of wave energy device models from numerical wave tank data - part 1: numerical wave tank identification tests. IEEE Trans Sustain Energy 2016;7(3):1012-9.

[165] Devolder B, Rauwoens O, Troch P. Numerical simulation of a single floating point absorber wave energy converter using OpenFOAM. In: Proceedings of the 2nd International Conference on Renewable Energies Offshore, 2016.

[166] Elhanafi A. Prediction of regular wave loads on a fixed offshore oscillating water column-wave energy converter using CFD. J Ocean Eng Sci 2016;1(4):268-83.

[167] Elhanafi A, Fleming A, Macfarlane G, Leong Z. Numerical energy balance analysis for an onshore oscillating water column-wave energy converter. Energy 2016;116:539-57.

[168] Ferrer PM, Causon D, Qian L, Mingham C, Ma Z. A multi-region coupling scheme for compressible and incompressible flow solvers for two-phase flow in a numerical wave tank. Comput Fluids 2016;125:116-29.

[169] Ferrer PM, Causon DM, Qian L, Mingham CG, Ma ZH. Numerical simulation of wave slamming on a flap type oscillating wave energy device. In: Proceedings of the 26th International Ocean and Polar Engineering Conference, 2016.

[170] Giorgi G, Ringwood JV. Implementation of latching control in a numerical wave tank with regular waves. J Ocean Eng Mar Energy 2016;2:211-26.

[171] Giorgi G, Penalba M, Ringwood JV. Nonlinear hydrodynamic models for heaving buoy wave energy converters. In: Proceedings of the 3rd Asian Wave \& Tidal Energy Conference, 2016.

[172] Giorgi S, Davidson J, Ringwood JV. Identification of wave energy device models from numerical wave tank data-Part 2: data-based model determination. IEEE Trans Sustain Energy 2016;7:1020-7.

[173] Hu ZZ, Greaves D, Raby A. Numerical wave tank study of extreme waves and wave-structure interaction using OpenFOAM. Ocean Eng 2016;126:329-42.

[174] King A, Algie C, Ryan S, Ong R. Modelling of fluid structure interactions in submerged flexible membranes for the bombora wave energy converter. In: Proceedings of the 20th Australasian Fluid Mechanics Conference, 2016.

[175] Kim JW, Jang H, Baquet A, O'Sullivan J, Lee S, Kim B, Read A, Jasak H. Technical and economic readiness review of CFD-based numerical wave basin for offshore floater design. In: Proceedings of the Offshore Technology Conference, Society of
Petroleum Engineers (SPE), 2016

[176] Loh TT, Greaves D, Maeki T, Vuorinen M, Simmonds D, Kyte A. Numerical modelling of the WaveRoller device using OpenFOAM. In: Proceedings of the 3rd Asian Wave \& Tidal Energy Conference, 2016

[177] Palm J, Eskilsson C, Paredes GM, Bergdahl L. Coupled mooring analysis for floating wave energy converters using CFD: formulation and validation. Int J Mar Energy 2016;16:83-99.

[178] Rajagopalan K, Nihous G. Study of the force coefficients on plates using an open source numerical wave tank. Ocean Eng 2016;118:187-203.

[179] Ringwood J, Davidson J, Giorgi S. Identifying models using recorded data. In: Numerical Modelling of Wave Energy Converters, Elsevier, 2016, p. 123-47.

[180] Schmitt P, Asmuth H, Elsäßer B. Optimising power take-off of an oscillating wave surge converter using high fidelity numerical simulations. Int J Mar Energy 2016;16:196-208.

[181] Torresi M, Scarpetta F, Martina G, Filianoti PF, Camporeale SM. Numerical prediction of the natural frequency of an oscillating water column operating under resonant conditions. Int J Ocean Clim Syst 2016;7:100-7.

[182] Torres FR, Teixeira PR, Didier E. Study of the turbine power output of an oscillating water column device by using a hydrodynamic - aerodynamic coupled model. Ocean Eng 2016;125:147-54.

[183] Windt C, Tchoufag J, Alam M. Numerical investigation of three-dimensional effects on wave excitation forces on a submerged rigid board. In: Proceedings of the 2nd International Conference on Offshore Renewable Energy, 2016.

[184] Wei Y, Abadie T, Henry A, Dias F. Wave ineraction with an Oscillating Wave Surge Converter.Part II: Slamming. Ocean Eng 2016;113:319-34.

[185] Allen J, Samapanis K, Wan J, Miles J, Greaves D, Iglesias G. Laboratory tests and numerical modelling in the development of WaveCat. In: Proceedings of the 12th European Wave and Tidal Energy Conference, 2017.

[186] Bouali B, Larbi S. Sequential optimization and performance prediction of an oscillating water column wave energy converter. Ocean Eng 2017;131:162-73.

[187] Bridgwater Court J, Cahndel D, Plummer A, Hillis A. Modelling of Array Interactions for a Curved OSWEC using OpenFOAM. In: Proceedings of the 12th European Wave and Tidal Energy Conference, 2017.

[188] Dolguntseva I, Chen W, Savin A, Zhang Y, Li W, Svensson O, et al. Numerical modelling of a point-absorbing wave energy converter in irregular and extreme waves. Appl Ocean Res 2017;63:90-105.

[189] Davidson J, Windt C, Giorgi G, Genest R, Ringwood J. Evaluation of energy maximising control systems for wave energy converters using OpenFOAM. In: Proceedings of the 11th OpenFOAM Workshop, Springer International Publishing AG, 2017.

[190] Davidson J, Genest R, Ringwood J. Adaptive control of a wave energy converter simulated in a numerical wave tank. In: Proceedings of the 12th European Wave and Tidal Energy Conference, 2017

[191] Devolder B, Rauwoens P, Troch P. Numerical simulation of an array of heaving floating point absorber wave energy converters using openfoam. In: Proceedings of the VII International Conference on Computational Methods in Marine Engineering, 2017

[192] Devolder B, Rauwoens P, Troch P. Towards the numerical simulation of 5 floating point absorber wave energy converts installed in a line array using OpenFOAM. In: Proceedings of the 12th European Wave and Tidal Energy Conference, 2017.

[193] Elhanafi A, Macfarlane G, Fleming A, Leong Z. Investigations on 3d effects and correlation between wave height and lip submergence of an offshore stationary OWC wave energy converter. Appl Ocean Res 2017;64:203-16.

[194] Elhanafi A, Fleming A, Macfarlane G, Leong Z. Numerical hydrodynamic analysis of an offshore stationary-floating oscillating water column-wave energy converter using CFD. Int J Nav Archit Ocean Eng 2017;9:77-99.

[195] Elhanafi A, Macfarlane G, Fleming A, Leong Z. Scaling and air compressibility effects on a three-dimensional offshore stationary OWC wave energy converter. Appl Energy 2017;189:1-20.

[196] Elhanafi A, Fleming A, Macfarlane G, Leong Z. Underwater geometrical impact on the hydrodynamic performance of an offshore oscillating water column-wave energy converter. Renew Energy 2017;105:209-31.

[197] Elhanafi A, Macfarlane G, Leong AFanZ. Experimental and numerical measurements of wave forces on a $3 \mathrm{~d}$ offshore stationary OWC wave energy converter. Ocean Eng 2017;144:98-117.

[198] Elhanafi A, Macfarlane G, Leong AFanZ. Experimental and numerical investigations on the intact and damage survivability of a floating-moored oscillating water column device. Appl Ocean Res 2017;68:276-92.

[199] Elhanafi A, Macfarlane G, Leong AFanZ. Experimental and numerical investigations on the hydrodynamic performance of a floating-moored oscillating water column wave energy converter. Appl Energy 2017;205:369-90.

[200] Eskilsson C, Palm J, Bergdahl L. On numerical uncertainty of VOF-RANS simulations of wave energy converters through V\&V technique. In: Proceedings of the 12th European Wave and Tidal Energy Conference, 2017.

[201] Eskilsson C, Wang W, Wu M, Palm J. Estimation of numerical uncertainty in CFD simulations of a passivley controlled wave energy converter. Proc Inst Mech Eng, Part M: J Eng Marit Environ 2017;232:71-84.

[202] Ghasemi A, Anbarsooz M, Malvandi A, Ghasemi A, Hedayati F. A nonlinear computational modeling of wave energy converters: A tethered point absorber and a bottom-hinged flap device. Renew Energy 2017;103:774-85.

[203] Giorgi G, Ringwood J. Consistency of viscous drag identification tests for wave energy applications. In: Proceedings of the 12th European Wave and Tidal Energy Conference, 2017.

[204] Lo D, Hsu T-W, Yang C-D. Hydrodynamic performances of wave pass two buoystype wave energy converter. In: Proceedings of the 27th International Ocean and Polar Engineering Conference, 2017. 
[205] Loh TT, Pizer D, Simmonds D, Kyte A, Greaves D. Simulation and analysis of wavestructure interactions for a semi-immersed horizontal cylinder. Ocean Eng 2017;145:1-14.

[206] Meng F, Rafiee A, Cazzolato B, Ding B, Arjomandi M, Piper JD, Sergiienko N, Hu Q. Numerical simulation of a submerged spherical point absorber with asymmetric mass distribution. In: Proceedings of the 12th European Wave and Tidal Energy Conference, 2017.

[207] Mundon TR, Rosenberg BJ, van Rij J. Reaction body hydrodynamics for a multiDOF point-absorbing WEC. In: Proceedings of the 12th European Wave and Tidal Energy Conference, 2017.

[208] Musiedlak P-H, Ransley E, Greaves D, Hann M, Iglesias G, Child B. Investigation of Model Validity for Numerical Survivability Testing of WECs. In: Proceedings of the 12th European Wave and Tidal Energy Conference, 2017.

[209] Connell KO, Cashman A, Thiebaut F, Kelly G. Development of a free heaving OWC model with non-linear pto interaction. Renew Energy 2017;205:369-90.

[210] Pilechi A, Baker S, Cornett A. Validation of a CFD tool for studying the behaviour of wave energy converters. In: Proceedings of the 12th European Wave and Tidal Energy Conference, 2017.

[211] Prasad DD, Ahmed MR, Lee Y-H, Sharma RN. Validation of a piston type wavemaker using numerical wave tank. Ocean Eng 2017;131:57-67.

[212] Ransley E, Greaves D, Raby A, Simmonds D, Hann M. Survivability of wave energy converters using CFD. Renew Energy 2017;109:235-47.

[213] Ransley E, Greaves D, Raby A, Simmonds D, Jakobsen M, Kramer M. RANS-VOF modelling of the wavestar point absorber. Renew Energy 2017;109:49-65.

[214] van Rij J, Yu Y-H, Guo Y. Structural loads analysis for wave energy converters. In: Proceedings of the 36th International Conference on Ocean, Offshore, and Arctic Engineering, 2017.

[215] Scarpetta F, Torresi M, Camporeale SM, Filianoti PF. CFD simulation of the unsteady flow in an Oscillating Water Column: comparison between numerical and experimental results for a small scale experimental device. In: Proceedings of the 12th European Wave and Tidal Energy Conference, 2017.

[216] Schmitt P, Elsässer B. The application of froude scaling to model tests of oscillating wave surge converters. Ocean Eng 2017;141:108-15.

[217] Simonetti I, Cappietti L. A CFD study on the balance of energy in a fixed bottomdetached oscillating water column wave energy converter. In: Proceedings of the 12th European Wave and Tidal Energy Conference, 2017.

[218] Simonetti I, Cappietti L, Elsafti H, Oumeraci H. Optimization of the geometry and the turbine induced damping for fixed detached and asymmetric OWC devices: a numerical study. Energy 2017;139:1197-209.

[219] Simonetti I, Cappietti L, Elsafti H, Oumeraci H. Evaluation of air compressibility effects on the performance of fixed OWC wave energy converters using CFD modelling. Renew Energy 2017;119:741-53.

[220] Sökvist L, Göteman M, Leijon M. Survivability of a point absorbing wave energy converter impacted by tsunami waves. In: Proceedings of the 12th European Wave and Tidal Energy Conference, 2017.

[221] Sökvist L, Wu J, Ransley E, Engström J, Eriksson M, Göteman M. Numerical models for the motion and forces of point-absorbing wave energy converters in extreme waves. Ocean Eng 2017;145:1-14.

[222] Vyzikas T, Deshoulieres S, Giroux O, Barton M, Greaves D. Numerical Study of fixed Oscillatin Water Column with RANS-type two-phase CFD model. Renew Energy 2017;102:294-305.

[223] Windt C, Davidson J, Schmitt P, Ringwood JV. Assessment of numerical wave makers. In: Proceedings of the 12th European Wave and Tidal Energy Conference, 2017.

[224] Wei Y, Rafiee A, Henry A, Dias F. Wave interaction with an oscillating wave surge converter, Part I: viscous effects. Ocean Eng 2015;104:185-203.

[225] Clément A, McCullen P, Falcão A, Fiorentino A, Gardner F, Hammarlund K, et al. Wave energy in europe: current status and perspectives. Renew Sustain Energy Rev 2002;6(5):405-31.

[226] EMEC, EMEC, last [Accessed 27 May 2017]. URL 〈http://www.emec.org.uk/ marine-energy/wave-devices/ $>$.

[227] Davidson J, Ringwood JV. Mathematical modelling of mooring systems for wave energy converters - A review. Energies 2017;10:666-712.

[228] Atkins Concultants WS. Sirehna, HSVA, FLOWTECH, VVT, Imperial College of Science \& Technology, Germanischer Lloyd, Astilleros Espanoles, Best practice guidelines for marine applications of computational fluid dynamics, Tech. rep., MARINET CFD (2002).

[229] Eça L, Toxopeus S, Terwisga Tv, Streckwall H. Best Practice Guidelines for the application of Computational Fluid Dynamics in Marine Hydrodynamics, Tech. rep., VIRTUE - The Virtuel Tank Utility in Europe, Affiliation: VIRTUE Project (2009).

[230] ITTC, Practical Guidelines for Ship CFD Applications, Tech. rep., In: Proceedings of the International Towing Tank Conference (2011).

[231] Roache PJ. Quantification of uncertainty in computational fluid dynamics. Annu Rev Fluid Mech 1997;26:123-60.

[232] Roache PJ. Verification and validation in computational science and engineering, Vol. 895, Hermosa Publisher Albuquerque, NM, 1998.

[233] Celik IB, Ghia U, Roache PJ, Freitas CJ, Coleman H, Raad PE. Procedure for estimation and reporting of uncertainty due to discretization in CFD applications. J Fluids Eng 2008;130:078001.

[234] Eça L, Vaz G, Hoekstra M. A verification and validation exercise for the flow over a backward facing step. In: Proceedings of the V European Conference on Computational Fluid Dynamics, 2010

[235] Eça L, Hoekstra M. A procedure for the estimation of the numerical uncertainty of CFD calculations based on grid refinement studies. J Comput Phys 2014;262:104-30.

[236] Sumer B, Fredsoe J. Hydrodynamics around cylindrical structures 26. World Scientific; 2006.

[237] Pope SB. Turbulent flows. Cambridge University Pr.; 2000.

[238] de Villiers E. The potential of large eddy simulation for the modeling2155 of wall bounded ows (Ph.D. thesis). Thermouids Section, Departmentof Mechanical Engineering, Imperial College of Science, Technology andMedicine; 2006.

[239] Launder BE, Spalding DB. The numerical computation of turbulent flows. Comput Methods Appl Mech Eng 1974:3:269-89.

[240] ANSYS, ANSYS Fluent V2F Turbulence Model Manual (2013).

[241] Shih T-H, Liou WW, Shabbir A, Yang Z, Zhu J. A new k- eddy viscosity model for high reynolds number turbulent flows. Comput Fluids 1995;24(3):227-38.

[242] cfd online, Relisable k-epislon model, last [Accessed 22/05/207] (2017). URL 〈https://www.cfd-online.com/Wiki/Realisable_k-epsilon_model〉.

[243] Yakhot V, Orszag SA, Thangam S, Gatski TB, Speziale CG. Development of turbulence models for shear flows by a double expansion technique. Phys Fluids A: Fluid Dyn 1992;4:1510-20.

[244] cfd online, Relisable RNG k-epislon model, last [Accessed 22/05/207] (2017). URL 〈https://www.cfd-online.com/Wiki/RNG k-epsilon model〉.

[245] ANSYS, Inc., ANSYS Fluent Theory Guide v16.1 (04 2015).

[246] Wilcox DC. Reassessment of the scale-determining equation for advanced turbulence models. AIAA J 1988;26:1299-310.

[247] Wilcox DC. Comparison of two-equation turbulence models for boundary layers with pressure gradient. AIAA J 1993;31:1414-21.

[248] Wilcox DC. Turbulence Modeling for CFD. DCW Ind 1993.

[249] Wilcox DC. Simulation of transition with a two-equation turbulence model. AIAA J 1994;32:247-55.

[250] Menter FR. Improved Two-equation k- $\omega$ Turbulence Models for Aerodynamic Flows, Tech. rep., NASA Technical Memorandum TM-103975 (1992).

[251] Schmitt P, Elsaesser B. A Review of Wave Makers for 3D numerical Simulations. In: Proceedings of the 6th International Conference on Computational Methods in Marine Engineering, 2015.

[252] Afshar MA. Numerical wave generation in OpenFOAM (Master's thesis). Department of Shipping and Marine Technology Chalmers University ofTechnology; 2010.

[253] Jacobsen N, Fuhrmann DR, Fredsoe J. A wave generation toolbox for the opensource CFD library: OpenFoam. Int J Numer Methods Fluids 2012:70:1073-88.

[254] Walker D, Taylor P, Taylor RE. The shape of large surface waves on the open sea and the draupner new year wave. Appl Ocean Res 2004;26:73-83.

[255] Higuera P. Application of computational uid dynamics to wave actionon structures (Ph.D. thesis). University of Cantabria, School of Civil Engineering; 2015.

[256] Higuera P, Lara JL, Losada IJ. Realistic wave generation and active wave absorption for Navier-Stokes models Application to OpenFOAM. Coast Eng 2013:72:102-18.

[257] Lin P, Liu PL-F. Internal wave-maker for navier-stokes equations models. J Waterw, Port, Coast, Ocean Eng 1999;125(4):207-15.

[258] Choi J, Yoon SB. Numerical simulations using momentum source wave-maker applied to RANS equation model. Coast Eng 2009;56:1043-60.

[259] Sommerfeld A. Partial differential equations in physics. Academic Press; 1949.

[260] Causon D, Ingram D, Mingham C, Yang G, Pearson R. Calculation of shallow water flows using a cartesian cut cell approach. Adv Water Resour 2000;23:545-62.

[261] Ingram D, Causon D, Mingham C. Developments in cartesian cut cell methods. Math Comput Simul 2003;61:561-72.

[262] Garcia-Rosa PB, Costello R, Dias F, Ringwood JV. Hydrodynamic modelling competition - overview and approach. In: Proceedings of the ASME 34th International Conference on Ocean, Offshore and Arctic Engineering, 2015

[263] Benek J, Steger J, Dougherty F. A flexible grid embedding technique with application to the euler equations. In: Proceedings of the 6th Computational Fluid Dynamics Conference Danvers, American Institute of Aeronautics and Astronautics, 1983.

[264] Sharma N, Patankar NA. A fast computation technique for the direct numerical simulation of rigid particulate flows. J Comput Phys 2005;205:439-57.

[265] Wei G. A fixed-mesh method for general moving objects in fluid flow. Mod Phys Lett B 2005;19:1719-22. [28n29].

[266] Pearson K. Note on regression and inheritance in the case of two parents. Proc R Soc Lond 1895;58:240-2.

[267] Weller HG, Tabor G, Jasak H, Fureby C. A tensorial approach to computational continuum mechanics using object-oriented techniques. Comput Physic 1998;12:620-31.

[268] Masterton S, Swan C. On the accurate and efficient calibration of a 3d wave basin. Ocean Eng 2008;35:763-73. 